\title{
A simple role for BDNF in learning and memory?
}

\author{
Carla Cunha ${ }^{1,2}$, Riccardo Brambilla ${ }^{3}$ and Kerrie L. Thomas ${ }^{4 *}$ \\ Department of Biotechnology and Biosciences, University of Milano-Bicocca, Milan, Italy \\ 2 Center for Nanomedicine and Tissue Engineering, A.O. Ospedale Niguarda Ca' Granda, Milan, Italy \\ ${ }^{3}$ San Raffaele Scientific Institute and University, Milan, Italy \\ ${ }^{4}$ Cardiff School of Biosciences, Cardiff University, Cardiff, UK
}

\section{Edited by:}

Seth G.N. Grant, The Wellcome Trust

Sanger Institute, UK

Reviewed by:

Ted Abel, University of Pennsylvania, USA

Peter C. Kind, University of Edinburgh UK

\section{${ }^{*}$ Correspondence:}

Kerrie L. Thomas, Cardiff School of Biosciences, Cardiff University,

Museum Avenue, Cardiff CF10 3AX

UK

e-mail:ThomasKL5@cf.ac.uk
Since its discovery almost three decades ago, the secreted neurotrophin brain-derived neurotrophic factor (BDNF) has been firmly implicated in the differentiation and survival of neurons of the CNS. More recently, BDNF has also emerged as an important regulator of synaptogenesis and synaptic plasticity mechanisms underlying learning and memory in the adult CNS. In this review we will discuss our knowledge about the multiple intracellular signalling pathways activated by BDNF, and the role of this neurotrophin in long-term synaptic plasticity and memory formation as well as in synaptogenesis. We will show that maturation of BDNF, its cellular localization and its ability to regulate both excitatory and inhibitory synapses in the CNS may result in conflicting alterations in synaptic plasticity and memory formation. Lack of a precise knowledge about the mechanisms by which BDNF influences higher cognitive functions and complex behaviours may constitute a severe limitation in the possibility to devise BDNF-based therapeutics for human disorders of the CNS.

Keywords: BDNF, cell signalling, synaptogenesis, synaptic plasticity, learning and memory, behaviour

\section{INTRODUCTION}

The ability to store and recall information is one of the most amazing capacities of higher organisms. In recent years, our understanding of the basic molecular and cellular mechanisms underlying cognitive processing and behaviour has considerably advanced, providing not only the basis for future therapy of memory disorders, but also for slowing down normal age-related cognitive decline in humans. Studies of learning and memory in animal models have identified a number of gene products that are necessary for these processes. Among them is brain-derived neurotrophic factor (BDNF). BDNF was first purified from the mammalian brain based on its survivalpromoting action on dorsal root ganglion cells (Barde et al., 1982), and was classified as the second member of the neurotrophin family of growth factors, after nerve growth factor (NGF; Cohen et al., 1954). Neurotrophins are required for the development of the nervous system of vertebrates, and the family also includes neurotrophin3 (NT3), neurotrophin-4/5, neurotrophin-6 and neurotrophin-7. Among neurotrophins, BDNF, and its major receptor $\operatorname{TrkB}$, has the most abundant and widespread expression in the developing and adult mammalian brain (Murer et al., 2001). Likewise, the action of this neurotrophin in the adult CNS is now the most extensively studied, probably because it has been shown to have a critical role in long-term potentiation (LTP), a form of synaptic plasticity which is still widely considered a cellular model of long-term memory (LTM) formation (Bliss and Collingridge, 1993; Martin et al., 2000).

\section{BDNF ROLE IN SYNAPTIC PLASTICITY: CELLULAR AND MOLECULAR DYNAMICS BEHIND THE SCENE ACTIVITY-DEPENDENT BDNF REGULATION AND RELEASE}

The structural organization of the $B d n f$ gene has recently been reviewed for mouse and rat (Liu et al., 2006; Aid et al., 2007), and for human (Liu et al., 2005). Its structure and regulation is complex: a total of 9 promoters produce 24 different transcripts, all of them translated into an identical mature dimeric protein, suggesting a multilevel regulation of expression (Figure 1). Indeed, BDNF promoters are individually recruited to direct the tissue-specific expression of the different BDNF transcripts. Moreover, specific exon-containing transcripts are differentially regulated by a variety of stimuli, which regulate neuronal activity such as physical exercise, seizures, ischemia, osmotic stress, and antidepressant treatment. It is thought that the different exons may have different functions particularly with relation to the intracellular targeting and the availability of BDNF by controlling translation and/or stability. Protein non-coding antisense transcripts are expressed from the human $B D N F$ gene locus. These may function as another level of complexity in the regulation of $B D N F$ gene expression in vivo.

$\mathrm{BDNF}$ protein is synthesized as a precursor, pre-proBDNF protein, resulting after cleavage in a $32-\mathrm{kD}$ a proBDNF protein. ProBDNF is either proteolytically cleaved intracellularly by enzymes like furin or pro-convertases and secreted as the $14 \mathrm{kDa}$ mature BDNF (mBDNF), or secreted as proBDNF and then cleaved by extracellular proteases, such as metalloproteinases and plasmin, to $\mathrm{mBDNF}$ (reviewed in Lessmann et al., 2003). The extent of intracellular and extracellular processing of proBDNF is not exactly clear, but proBDNF is less efficiently processed by intracellular proteases compared to other neurotrophins and secretion of proBDNF with respect to $\mathrm{mBDNF}$ seems to prevail (Mowla et al., 2001). Nevertheless, both proBDNF and mBDNF are preferentially sorted and packaged into vesicles of the activity-regulated secretory pathway. ProBDNF is not an inactive precursor of BDNF, but rather it is a signalling protein in its own right (see below). ProBDNF is released in the immature and mature CNS in an activity dependent manner (Mowla et al., 2001; Yang et al., 2009; Figure 2). The intracellular localization of $\mathrm{BDNF}$ is predominantly somatodendritic but it is also enriched 


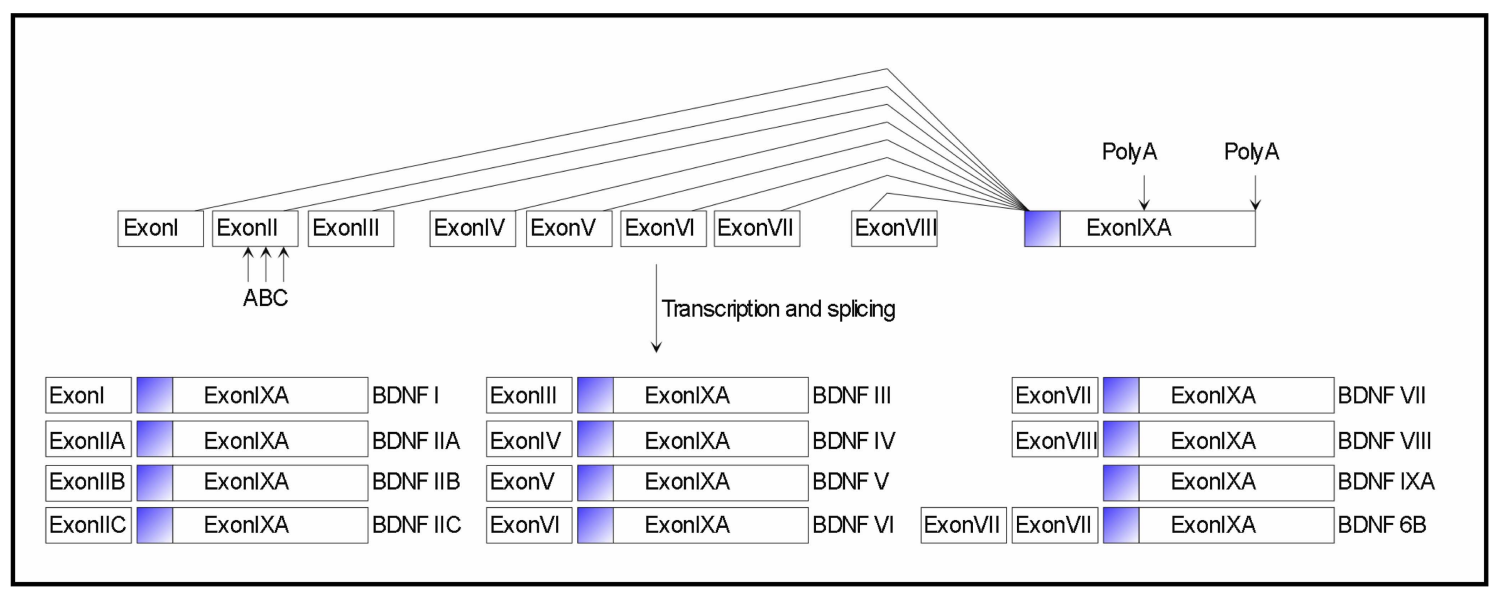

FIGURE 1 | Mouse and rat Bdnf gene structure and transcripts. Exons are indicated by boxes. Filled box in exon IXA indicates the coding region of the Bdnf gene. Lines indicate splice variants. Arrows indicate within-exon splice sites and alternative polyadenylation sites. The Bdnf gene is transcribed from different promoters, immediately preceding each of the $5^{\prime}$ exons (exons I-VIII), so that each full-length transcript contains a unique $5^{\prime}$-exon and a common $3^{\prime}$-exon (exon IXA) that encodes the BDNF protein. Transcript BDNF6B results from splicing events that incorporate exons VII, VIII and IXA. in the dendrites, where it is also synthesized from mRNA in close proximity to spines (reviewed in Tongiorgi et al., 1997; Tongiorgi, 2008). BDNF is present in pre- and postsynaptic compartments and it can undergo both retrograde and anterograde transport. Moreover, BDNF can act via autocrine and paracrine mechanisms, depending on the site of cell surface receptors through which it signals (reviewed in Murer et al., 2001). The activity-regulated release of BDNF can occur via three mechanisms dependent on the site of release: (i) $\mathrm{Ca}^{2+}$ influx-dependent release from postsynaptic sites, which is mediated by $\mathrm{Ca}^{2+}$ influx through ionotropic glutamate receptors and voltage gated $\mathrm{Ca}^{2+}$-channels (Hartmann et al., 2001), (ii) $\mathrm{Ca}^{2+}$ influx-dependent release from presynaptic sites (Balkowiec and Katz, 2002), and (iii) $\mathrm{Ca}^{2+}$ influx-independent release that relies on $\mathrm{Ca}^{2+}$ release from intracellular stores (Griesbeck et al., 1999). Neuronal activity also regulates the transport of BDNF mRNA and protein into dendrites (reviewed in Tongiorgi et al., 1997; Tongiorgi, 2008), and these mechanisms are considered to be responsible for the ability of locally translated BDNF to modulate synaptic transmission and synaptogenesis (reviewed in Lu and Figurov, 1997). Evidence of the importance for the regulated trafficking of BDNF to cognitive function comes from the only single nucleotide polymorphism (SNP) identified in the human BDNF gene, Val66Met (Egan et al., 2003). This SNP consists in the substitution of Met for Val at position 66 in the pro-region of BDNF which not only alters the trafficking, distribution and activity-dependent release of BDNF from neurons but also results in memory impairments in rodent models and in an increased susceptibility towards disorders such as depression, bipolar disorder and eating disorder in humans carrying the mutation (Chen et al., 2004).

\section{BDNF-DEPENDENT SIGNALLING PATHWAYS AND THEIR TARGETS}

BDNF binds and activates, both pre- and postsynaptically, two different transmembrane receptor proteins: the tropomyosin related kinase TrkB receptor with high affinity, and the pan neurotrophin receptor $\mathrm{p} 75^{\mathrm{NTR}}$ with low affinity (see Figure 3 ). At present, virtually all the synaptic effects of BDNF are attributed to TrkB activation.
However, there is evidence that proBDNFbinds $\mathrm{p} 75^{\mathrm{NTR}}$ preferentially (Teng et al., 2005), which has distinct functional consequences (see below). BDNF can also bind TrkB splice variants lacking the tyrosine kinase domain required for downstream signalling, which are found mainly, but not exclusively, in glial cells (Klein et al., 1990). Therefore, the binding of BDNF to these TrkB variant receptors can act as a dominant-negative inhibitor of BDNF signalling by forming heterodimers with the full-length $\operatorname{TrkB}$, and by internalizing BDNF to function as a clearance receptor (Haapasalo et al., 2002). ProBDNF, p75 ${ }^{\mathrm{NTR}}$ and truncated TrkB isoforms can therefore be considered as negative regulatory mechanisms of the canonical BDNF-TrkB association, with consequent effects for synaptic plasticity and perhaps learning and memory.

TrkB activation by BDNF follows the general scheme for receptor tyrosine kinases and initiates three major cascades of signalling pathways: phospholipase $\mathrm{C} \gamma$ (PLC $\gamma$ ), phosphatidylinositol 3-kinase (PI3K), and the well-characterized cascade governed by extracellular signal-regulated kinases (ERK), member of the mitogenactivated protein kinase (MAPK) family (reviewed in Segal, 2003; Figure 3). TrkB receptor activation by BDNF results in its dimerization and in the autophosphorylation of specific tyrosine residues in its cytoplasmic kinase domain. Transphosphorylation of Y785 recruits PLC $\gamma$. Activation of this pathway is directly implicated in a rise of intracellular $\mathrm{Ca}^{2+}$ via its release from intracellular stores, and in the activation of the $\mathrm{Ca}^{2+}$-calmodulin dependent kinase, CaMKII. The elevation of intracellular $\mathrm{Ca}^{2+}$ is one of the most important biochemical outcomes of BDNF signalling in the postsynaptic cell. Especially exciting evidence indicates that $\mathrm{Ca}^{2+}$-regulated mRNA translation occurs locally at postsynaptic sites (Wu et al., 1998; Aakalu et al., 2001). This mechanism provides a means for the rapid and accurate expression of activity-induced gene products such as BDNF at activated synapses. Moreover, the CaMKII activated transcription factor CREB has been shown to recognize CRE and a $\mathrm{CaRE}$ regulatory elements in the $B d n f$ gene, activating its transcription (reviewed in West et al., 2002). Thus, BDNF can regulate its own expression via activation of CaMKII signalling. 


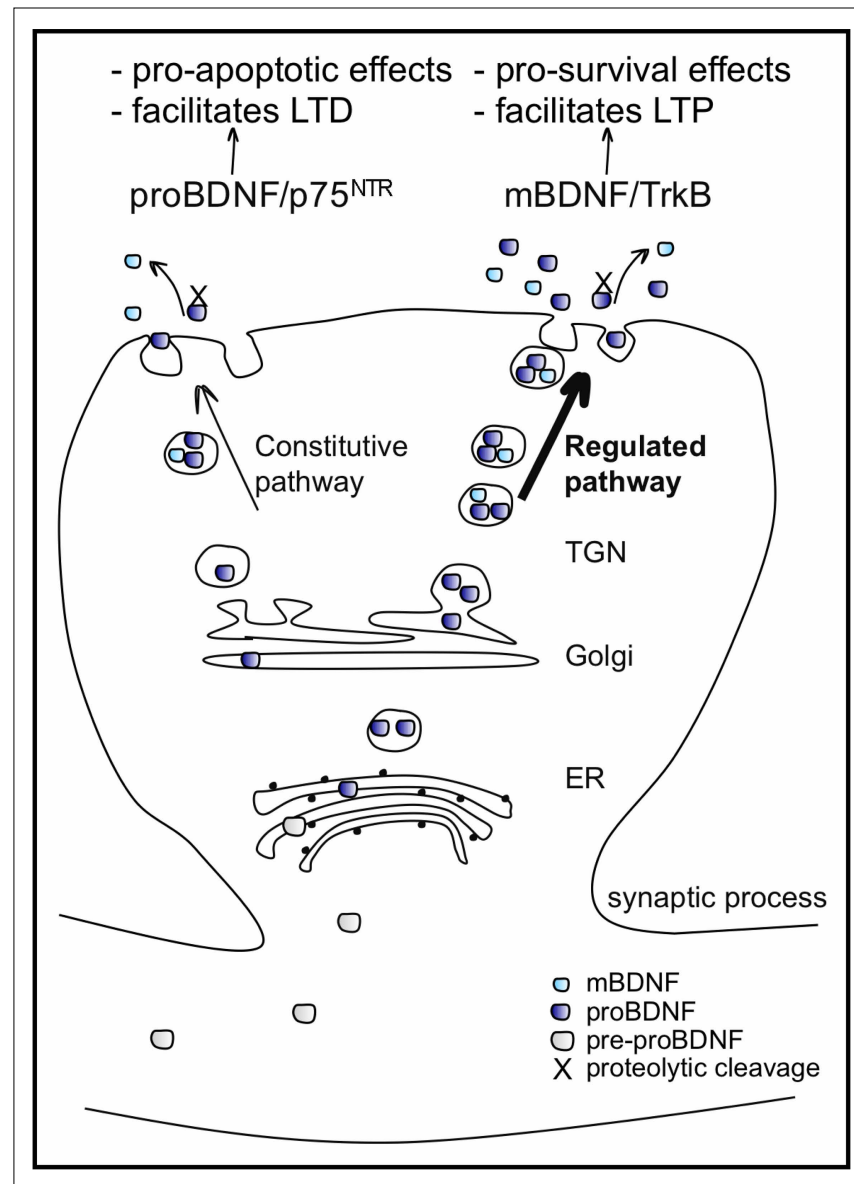

FIGURE 2 | BDNF processing, packaging and secretion in neurons. BDNF is synthesized as a pre-proBDNF protein, which has its pre-sequence cleaved off in the endoplasmic reticulum (ER). The resulting 32-kDa proBDNF moves, via the Golgi apparatus, into the trans-Golgi network (TGN) where two kinds of secretory vesicles are generated: those of the constitutive secretory pathway and those of the regulated pathway, whose secretion is activity-dependent. ProBDNF packaged in both types of vesicles is either proteolytically cleaved and secreted as 14-kDa mBDNF, or secreted as proBDNF and cleaved by extracellular proteases. The extent of the intra and extracellular processing of proBDNF is not exactly clear, but secretion of the proBDNF predominates. Both proBDNF and mBDNF are preferentially packaged into vesicles of the regulated secretory pathway. Once released, proBDNF binds preferentially to pan neurotrophin receptor $\mathrm{p} 75^{\mathrm{NTR}}$ and $\mathrm{mBDNF}$ binds preferentially to both pre-and post-synaptic TrkB receptors, activating different intracellular secondary messenger cascades and affecting distinct cellular responses.

The transphosphorylation of TrkB Y490 upon BDNF binding permits the association of SH2 (src homology-type 2) linker proteins such as shc (src homology domain containing) and insulin receptor substrate-1 and -2 (IRS2, IRS2). This event leads to the activation of the PI3K and ERK signalling pathways. Src sequentially recruits an intermediary protein Grb2 and the guanine nucleotide exchange factor SOS, initiating the GTP loading and activation of Ras and the activation of the Raf, MEK and ERK kinase cascade. Phosphorylated ERK translocates to the nucleus to activate transcription factors such as CREB to regulate gene expression. Grb2 can also recruit another intermediary binding protein, Gab1 to activate PI3K and the downstream kinase, Akt (also known as protein kinase B). BDNF can also activate the PI3K pathway via a direct interaction between IRS1/IRS2 and PI3K (Yamada et al., 1997). The PI3K pathway was shown to mediate the protective effects of BDNF in several neuronal cell types in vitro, including hippocampal neurons (Zheng and Quirion, 2004). Ras was the first neurotrophin-activated signalling protein shown to mediate neuronal survival (reviewed in Kaplan and Miller, 2000), which can involve Ras-mediated activation of PI3K, however, Ras-dependent neuronal survival is also mediated by the ERK pathway. BDNF was also shown to facilitate local translation of proteins in dendrites by activation of mammalian target of rapamycin (mTOR) via PI3K (Schratt et al., 2004). Both mTOR and ERK are able to regulate the assembly of the eIF4e complex and phosphorylation of S6K1, both contributing to an enhanced mRNA translation initiation at active synapses (reviewed in Klann and Dever, 2004; Bramham and Wells, 2007). The differential activation and role of these cascades in neuronal survival will likely depend on the cell type and the involvement of specific physiological or pathological stimuli.

The activation of $\mathrm{p} 75^{\mathrm{NTR}}$ by BDNF initiates both prosurvival NF-kB and pro-apoptotic Jun kinase signalling cascades. $\mathrm{p} 75^{\mathrm{NTR}_{-}}$ mediated survival involves the activation of the NF-kB pathway via the association of $\mathrm{p} 75^{\mathrm{NTR}}$ with tumour necrosis factor receptor associated factor 4/6 (TRAF4/6) and receptor interacting protein-2 (RIP2, reviewed in Chao, 2003; Figure 3).

BDNF elicits rapid effects on synaptic transmission and membrane excitability primarily via activation of these signalling pathways. BDNF affects synaptic transmission by acting at pre- and postsynaptic sites. It can induce the presynaptic release of glutamate and GABA through TrkB-ERK-mediated phosphorylation of synapsin (Jovanovic et al., 2000). At least for glutamatergic synapses, the BDNF-induced enhancement in transmission is mediated by an increase in the number of docked vesicles at the active zones of synapses (Tyler and Pozzo-Miller, 2001). Postsynaptically, BDNF also rapidly modulates excitatory and inhibitory transmission by altering the activation kinetics of glutamatergic NMDA receptors and inhibitory GABA receptors (reviewed in Rose et al., 2004). While the inhibition of GABA transmission in the adult brain occurs via TrkB-PLC $\gamma$ signalling, the potentiation of NMDA receptor responses and enhancement in $\mathrm{Ca}^{2+}$ influx is meditated by a novel mechanism in which the src-family tyrosine kinase Fyn, activated by $\operatorname{TrkB}$, directly phosphorylates the NR2B subunit. BDNF also upregulates surface expression of AMPA receptors by inducing their rapid surface translocation to increase excitatory transmission (Narisawa-Saito et al., 2002; Itami et al., 2003), an effect that requires ERK signalling (Li and Keifer, 2009; Figure 4).

The modulation of membrane excitability by BDNF occurs through a range of mechanisms, as outlined in Figure 4; via TrkB activation of PLC $\gamma$ and the subsequent alteration in the activity of the nonselective cation TRPC3 channel (Li et al., 1999), the gating of the $\mathrm{Na}^{+}$channel $\mathrm{Na}_{\mathrm{v}} 1.9$ by an unknown BDNF-TrkB mechanism (Blum et al., 2002), and the increased gating probability of the voltage-gated potassium channel $\mathrm{K}_{\mathrm{v}} 1.3$ (Tucker and Fadool, 2002) and of the $G$ protein-gated potassium channel Kir3 (Ippolito et al., 2002). In addition, the effects of BDNF on neuronal excitability may also be in part mediated by the regulation of Arc/Arg3.1 activity. BDNF regulates the expression of the immediate early gene Arc/Arg3.1 (Yin et al., 2002; Ying et al., 2002). 


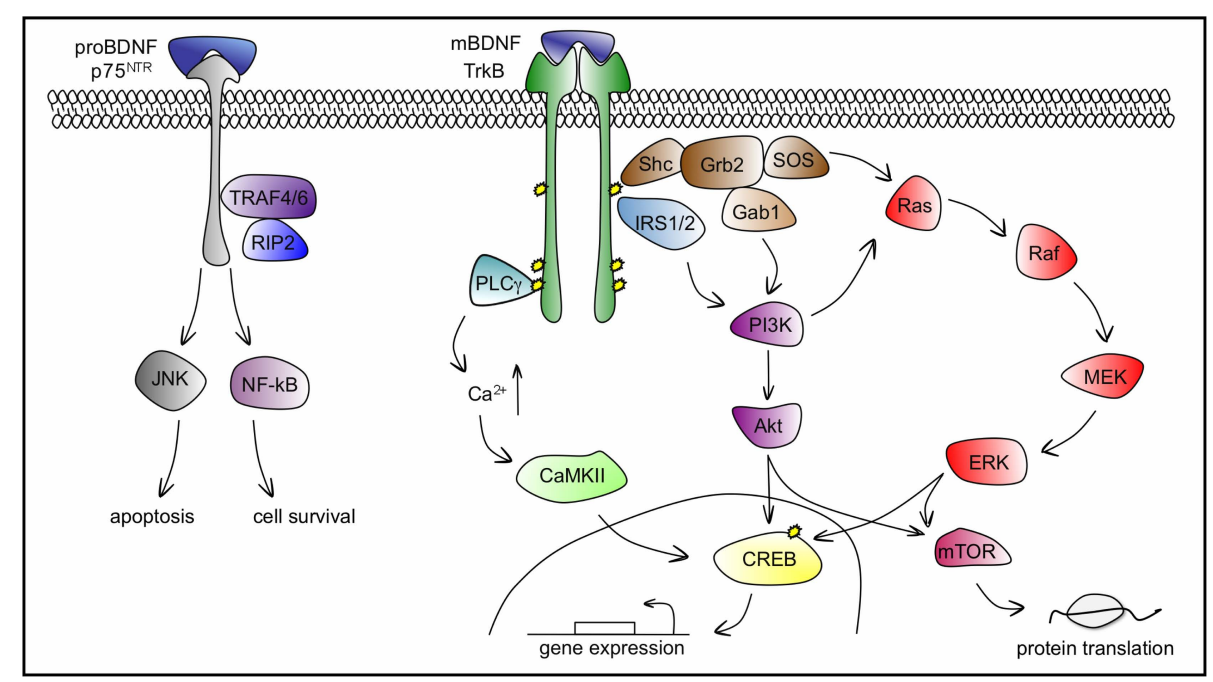

FIGURE 3 | BDNF-TrkB and BDNF-p75 ${ }^{\text {NTR }}$ signalling pathways. BDNF binds TrkB with high affinity to induce its dimerization and autophosphorylation of tyrosine residues in the cytoplasmic kinase domain that serve as docking sites for effector molecules and trigger the activation of three main signalling pathways: PLC $\gamma$, PI3K and ERK cascades, which ultimately lead to the phosphorylation and activation of the transcription factor CREB that mediates transcription of genes essential for the survival and differentiation of neurons. The recruitment of PLC $\gamma$ increases intracellular $\mathrm{Ca}^{2+}$ levels and leads to the activation of CaMKII to phosphorylate CREB. PI3K can be activated via the Shc/Grb2/SOS complex through Gab1 and by IRS1/2. Lipid products generated by the activated PI3K, the phosphatidylinositides, bind and activate protein kinase Akt, upstream of CREB. The ERK cascade can be activated both by the Shc/Grb2/SOS complex and by
PI3K. ERK phosphorylation leads directly to CREB phosphorylation. Both Akt and ERK activate $\mathrm{mTOR}$, responsible for enhanced translation initiation. BDNF binds p $75^{\text {NTR }}$ with low affinity, leading to apoptosis through the JNK cascade or cell survival through the NF-kB cascade. PLC $\gamma$, phospholipase $\mathrm{C} \gamma$, PI3K, phosphatidylinositol 3-kinase; ERK, extracellular signal-regulated kinase; CaMKII, calcium-calmodulin dependent kinase; Shc, src homology domain containing; Grb2, growth factor receptor-bound protein 2; SOS, son of sevenless; Gab1, Grbassociated binder $1 ; \mathrm{IRS} 1 / 2$, insulin receptor substrates $1 / 2$; CREB, cAMP-calcium response element binding protein; Ras, GTP binding protein; Raf, Ras associated factor; MEK, MAP/Erk kinase; mTOR, mammalian target of rapamycin;TRAF4/6, tumour necrosis factor receptor associated factor 4/6; RIP2, receptor interacting protein 2; JNK, c-Jun N-terminal kinase; NF-kB, nuclear factor k B.

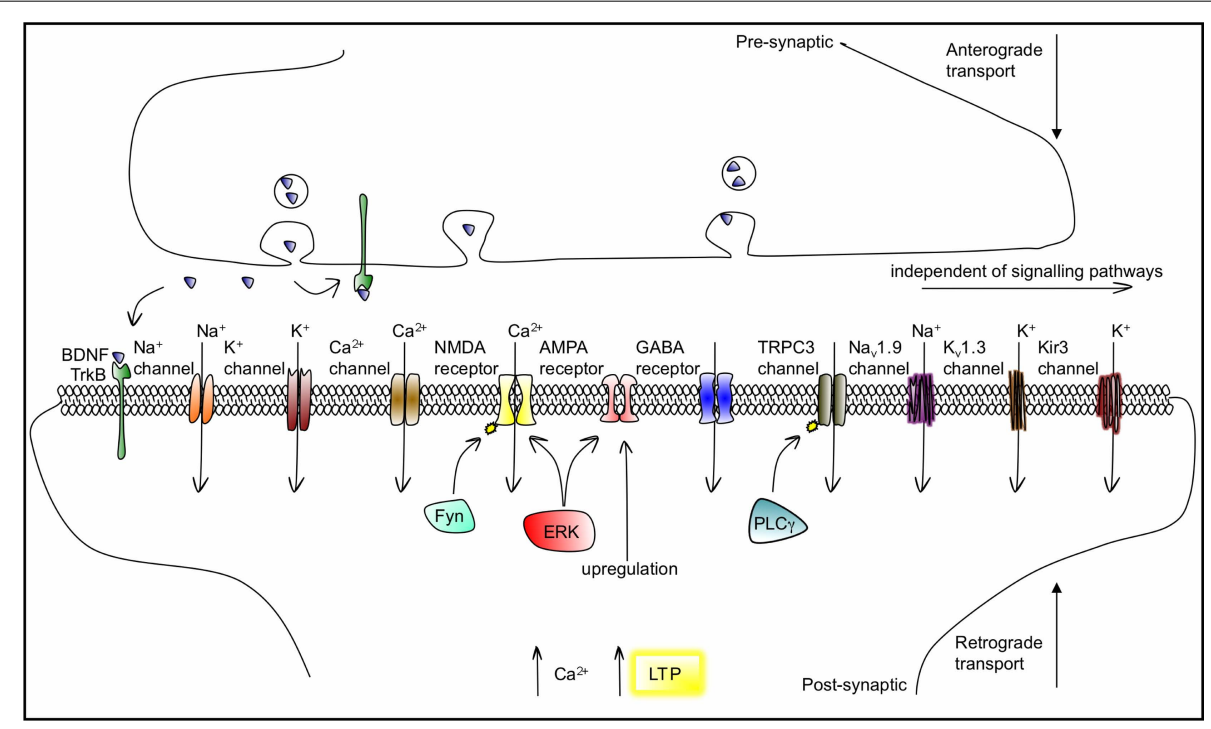

FIGURE 4 | BDNF/TrkB actions on ligand-gated, voltage-gated and second-messenger-gated ion channels, which mediate fast and slow synaptic transmission in neurons. BDNF is transported anterogradely and retrogradely and can activate TrkB receptors both pre- and postsynaptically. The association of BDNF with TrkB modulates or activates ion channels including $\mathrm{Na}^{+}, \mathrm{Ca}^{2+}$ and $\mathrm{K}^{+}$channels, within a range of seconds to minutes, through intracellular signalling cascades. TRPC3 is a non-selective cation channel that needs to be phosphorylated by TrkB to open, via PLC $\gamma$, a process also acting in the range of minutes. BDNF enhances glutamatergic neurotransmission by increasing open probability of NMDA (by promoting its phosphorylation, via Fyn-dependent and Fyn-independent mechanisms) and by upregulating AMPA expression. ERK signalling is involved in both NMDA and AMPA gating. In the millisecond range, BDNF/TrkB can directly gate the $\mathrm{Na}_{v} 1.9 \mathrm{Na}^{+}$, the $\mathrm{K}_{v} 1.3 \mathrm{~K}^{+}$and the $\mathrm{Kir} 3 \mathrm{~K}^{+}$ion channels. The resulting depolarizations contribute to the facilitation of the induction of LTP. 
The functions of Arc/Arg3.1 are not as yet fully understood. It is known that Arc/Arg3.1 interacts with, and regulates, the stabilization of the neuronal cytoskeleton and it can also regulate the postsynaptic trafficking of endosomes, particularly important for the expression of surface AMPA receptors at excitatory synapses (reviewed in Bramham et al., 2008). Both of these cellular processes are crucial to both basal synaptic transmission and synaptic plasticity. It thus appears that BDNF displays the properties of a classical neurotransmitter: presynaptic synthesis and vesicular storage, activity-dependent release, activation and targeting of specific postsynaptic receptors and fast ion channel gating (reviewed in Altar and DiStefano, 1998).

The role of multiple signalling mechanisms in learning and memory has been well documented, however the exact role that BDNF plays modulating these signalling pathways during learning remains to be elucidated. For example, mutant mice where the PLC $\gamma$ binding site of TrkB has been disrupted show impaired hippocampal LTP and associative learning, demonstrating the importance of PLC $\gamma$ signalling in hippocampal plasticity mechanisms (Minichiello et al., 2002; Gartner et al., 2006; Gruart et al., 2007). In addition, pivotal roles have already been shown for the ERK pathway (Orban et al., 1999; Sweatt, 2004; Thomas and Huganir, 2004), the PI3KAkt pathway (Lin et al., 2001) and the transcription factor CREB (Barco et al., 2003) in synaptic plasticity and learning and memory. Although there is no direct evidence for BDNF activation of the NF$\mathrm{kB}$ pathway in synaptic plasticity and LTM, a few studies have shown a contribution of the NF-kB signalling pathway in initial memory consolidation (Yeh et al., 2002; Freudenthal et al., 2005; Merlo et al., 2005). Thus, BDNF can activate multiple signalling pathways that may act in a concerted fashion to regulate downstream cellular effects necessary for synaptic plasticity and memory formation. The interaction between each of these intracellular pathways has to be further resolved, but the extent to which each of them is activated and selective biological responses initiated is likely to depend on the levels of BDNF and TrkB, the temporal pattern of BDNF stimulation and whether the signalling is activated pre- or postsynaptically.

There are multiple feedback systems that control the activity of BDNF. In addition to being able to increase its own transcription via a CREB mediated mechanism (Finkbeiner et al., 1997), BDNF can also increase the surface expression of TrkB (Haapasalo et al., 2002). Furthermore, it can regulate its own release (Canossa et al., 1997). These properties are likely to contribute to the reinforcement and stabilization of synaptic connections. Indeed, administration of exogenous BDNF itself can produce a form of synaptic potentiation that has all the hallmarks of LTP (reviewed in Bramham and Messaoudi, 2005). Nevertheless, prolonged exposure to BDNF induces a negative feedback loop by depleting TrkB receptors on the neuronal surface and resulting in long-term receptor desensitization to BDNF (Frank et al., 1996). Therefore, BDNF has a unique role in coupling neuronal activity to structural and functional properties of neuronal circuits.

In contrast to these rapid effects on synaptic transmission and membrane excitability, BDNF ultimately mediates slower cellular events. It is well established that, similar to other neurotrophins, BDNF promotes the differentiation, growth, target innervation and survival of neurons during the development of the central and peripheral nervous systems (Poo, 2001; Huang and Reichardt, 2003). However, much less is known about analogous functions in the adult brain. The importance of BDNF-mediated signalling for maintaining the survival and dendritic complexity of selective populations of neurons in the adult brain, including excitatory glutamatergic cortical neurons, has been established (Ghosh et al., 1994; Mamounas et al., 1995; Hu et al., 2005). However, the precise effects of BDNF on neuronal morphology are cell and layer specific. For example, BDNF promotes dendritic arborization of cortical neurons in layers IV, but inhibits dendritic arborization in layer VI (McAllister et al., 1995, 1997). Whilst BDNF overexpression in transgenic mice results in increases in dendritic complexity in the hippocampal dentate gyrus (Tolwani et al., 2002). The effects of BDNF to promote dendritic complexity are likely to be mediated by the activation of $\operatorname{TrkB}$, while activation of $\mathrm{p} 75^{\mathrm{NTR}}$ negatively regulates dendritic morphology (Zagrebelsky et al., 2005). With regards to cell survival in the adult brain, BDNF-mediated signalling prevents apoptosis of hippocampal and cerebellar granule cells (Minichiello and Klein, 1996; Alcantara et al., 1997). It is also a positive regulator of neurogenesis in the subgranular zone of the hippocampal dentate gyrus (Sairanen et al., 2005; Scharfman et al., 2005; Henry et al., 2007; Young et al., 2007).

\section{BDNF AND LTP}

LTP is the best studied form of synaptic plasticity and is considered as a cellular correlate of learning and memory. It is defined as an activity induced sustained increase in synaptic strength. The induction of LTP is associated with the activation of a large number of signalling cascades, including the ones activated by BDNF. Kafitz et al. (1999) showed that low concentrations of BDNF causes membrane depolarization of hippocampal, cortical and cerebellar neurons within a few milliseconds, leading to the firing of an action potential. This was a remarkable finding because, until then, only classic neurotransmitters had been found to have such a rapid effect on the membrane potential of neurons. Since then, substantial evidence has accumulated to indicate a critical role for BDNF in LTP induction, not only at hippocampal synapses at both the Schaffer collateral $\rightarrow$ CA1 synapse (Kang and Schuman, 1995) and in the dentate gyrus (Messaoudi et al., 2002), but also in the visual cortex (Akaneya et al., 1997).

Initially, in vitro studies showed that exogenous BDNF promoted the induction of LTP in young hippocampal slices (Figurov et al., 1996), and rapidly enhanced the frequency of miniature excitatory postsynaptic currents in solitary neurons (Taniguchi et al., 2000). Conversely, LTP was attenuated in slices pre-treated with function-blocking BDNF antibodies or the fusion protein TrkB-IgG, a molecular scavenger of endogenous BDNF (Figurov et al., 1996; Kang et al., 1997). Additional evidence for the role of BDNF in LTP was provided by studies with transgenic mice. Induction of LTP at the Schaffer collateral $\rightarrow$ CA1 synapse was severely impaired in two independent lines of BDNF null mutant mice. Similarly, cortical LTP impairment was observed in heterozygous BDNF mice of a third independently generated mutant (Bartoletti et al., 2002). Crucially, treatment of hippocampal slices from these transgenic mice with recombinant BDNF protein completely reversed deficits in LTP and significantly improved deficits in basal synaptic transmission at the Schaffer collateral /CA1 syn- 
apse (Korte et al., 1995; Patterson et al., 1996; Pozzo-Miller et al., 1999). These "rescue" experiments indicated that BDNF was the key mediator of LTP induction.

BDNF is essential for late phase LTP (L-LTP), which lasts at least $8 \mathrm{~h}$ after tetanization (Korte et al., 1998). L-LTP depends on both gene transcription and protein synthesis, and requires cAMP signalling and CREB (Kang et al., 1997; Korte et al., 1998). The conversion of proBDNF into $\mathrm{mBDNF}$ by protease tissue plasminogen activator (tPA)-activated plasmin is essential for hippocampal L-LTP (Pang et al., 2004). The application of mBDNF was sufficient to rescue L-LTP when protein synthesis was inhibited; suggesting that BDNF activated TrkB signalling is the key mechanism for L-LTP induction. Indeed, the concomitant blockade of TrkB signalling at pre- and postsynaptic sites impaired the induction of L-LTP (Gartner et al., 2006). The role of BDNF in L-LTP extends beyond the process of induction and is required for the maintenance L-LTP (Barco et al., 2005). The activation of cAMP signalling may function to trigger the release of BDNF and the insertion of TrkB receptor into the membrane in BDNF-dependent L-LTP (Patterson et al., 2001). LLTP is also associated with the activation of the ERK1/2 kinases, their translocation to the nucleus and the subsequent activation of CREB (Patterson et al., 2001). This may provide the mechanism that leads to the increase in BDNF mRNA expression in the hippocampus 2-4 h after application of tetanic stimulation (Castren et al., 1993; Dragunow et al., 1993). It remains to be seen whether delayed increases in BDNF release, TrkB insertion and BDNF expression contribute to the maintenance of L-LTP.

\section{BDNF AND LTM \\ LTM FORMATION}

The role of BDNF in learning and memory has been established by investigations in in vivo rodent models. BDNF mRNA expression was found to be increased in the hippocampus of rats following training in the Morris water maze (MWM; Kesslak et al., 1998), radial arm maze (Mizuno et al., 2000), passive avoidance (Ma et al., 1998) and contextual fear conditioning (Hall et al., 2000). Thus consistently indicating that the regulation of BDNF activity is a correlate of hippocampal learning in vivo. Interestingly, BDNF protein presents its highest expression in the hippocampus, neocortex, cerebellum, striatum and amygdala (Dugich-Djordjevic et al., 1995; Kawamoto et al., 1996), all key brain areas responsible for cognitive functions. Its regulation by learning also extends to these brain regions. For example, increases in BDNF mRNA and protein levels and TrkB phosphorylation were found in the amygdala following fear conditioning (Rattiner et al., 2004a). Furthermore, intra-hippocampal BDNF administration improved performance in MWM (Cirulli et al., 2004), and pre-training infusions of antiBDNF antibodies caused an impairment in MWM (Mu et al., 1999) and in passive avoidance (Alonso et al., 2002). Likewise, infusion of anti-BDNF antibodies into the parietal cortex impaired inhibitory avoidance by blocking CREB activation (Alonso et al., 2005). These studies strongly suggest that BDNF has an essential role in the consolidation of LTM in a wide range of behavioural protocols in wild-type animals.

Differential regulation of specific exon-containing BDNF transcripts has been associated with the consolidation of LTM, particularly exon I, IV and VI variants (Rattiner et al., 2004b; Chhatwal et al., 2006; Ou and Gean, 2007; Lubin et al., 2008). Furthermore, the changes in the expression of specific BDNF transcripts was associated with altered chromatin structure (Lubin et al., 2008), and the binding of active (phosphorylated) CREB (Ou and Gean, 2007 ) in the promoters proximal to these specific exons. In these latter studies, the administration of a NMDA receptor antagonist and a CREB decoy not only prevented the change in the expression of learning-associated BDNF variants but also attenuated the learning. This strongly suggests a casual relationship between NMDA receptor- and CREB-dependent mechanisms in regulating the expression of specific BDNF variants essential for LTM formation. Although all transcripts of BDNF are translated into an identical protein, some variants can be targeted to different cellular compartments, including dendrites for local translation at active synapses (reviewed in Tongiorgi, 2008). This "spatial code" for the delivery of BDNF mRNA to specific sites may be a key mechanism for regulating the local availability of BDNF to control cellular and synaptic events that underlie learning and memory.

In the 1990s, the advent of the technology to genetically modify mice, including the deletion (knockout, $\mathrm{KO}$ ) or overexpression of BDNF and TrkB, made it possible to determine a specific role for these gene products in synaptic plasticity and animal behaviour. New advances in these techniques now allow the inducible and reversible gene targeting in selected brain regions (conditional mutagenesis), the transgenic rescue of disrupted genes and the single-cell recording of hippocampal place cells in mutant mice. Early studies using $\mathrm{KO}$ animal models with global reductions of BDNF, revealed that BDNF null mutant mice die within 2 days after birth and only a small fraction live for 2-4 weeks (Ernfors et al., 1994). Although the CNS of these mutants shows no gross structural abnormalities, they displayed symptoms of nervous system dysfunction and had substantially reduced numbers of cranial and spinal sensory neurons. Heterozygous BDNF KO mice do not exhibit these abnormalities and have a normal life span, although they do present a serotonergic dysfunction (Lyons et al., 1999). LTP was significantly reduced in the CA1 region of the hippocampus of surviving homozygous mice and heterozygous $\mathrm{KO}$ mice (Ernfors et al., 1994). Heterozygous KO mice showed learning deficits in the MWM (Linnarsson et al., 1997) and in contextual fear conditioning (Lu et al., 2004).

TrkB KO mice showed a more severe phenotype than BDNF KO mice and the few mice that were able to survive up to 3 weeks displayed neuronal deficiencies in the CNS and PNS (Klein et al., 1993), and an increased number of apoptotic central neurons especially in the dentate gyrus (Alcantara et al., 1997). More recently, the generation of conditional BDNF KO mice circumvented the problem of postnatal lethality and of developmental effects, since gene disruption occurs only at defined time points and allows for some regional specificity of gene deletion. One conditional model, with the inducible loss of BDNF in forebrain regions of adult mice, showed impaired contextual fear conditioning and hippocampal LTP (Monteggia et al., 2004). Another conditional BDNF mutant (Emx-BDNF-KO), lacking BDNF from the early embryonic development specifically in forebrain regions, fail to learn the MWM task, although they also presented with mild obesity, shortened lifespan, increased inter-male aggressiveness and infertility which are indicative of more widespread brain dysfunction (Gorski et al., 
2003). More recently, using lentiviral delivery of CRE recombinase into the dorsal hippocampus of adult mice floxed at the BDNF locus, mice with a site-specific deletion of BDNF were generated. These mice showed an impairment in MWM and novel object recognition tests (Heldt et al., 2007). A conditional TrkB-CRE mutant mouse was generated, in which the deletion TrkB is restricted to the forebrain and occurred only postnatally. These mice showed severe deficits in hippocampus-dependent learning tasks such as MWM and eight-arm radial maze, and hippocampal LTP, but exhibited normal learning in the simple passive avoidance task (Minichiello et al., 1999). However, these mice also displayed a range of nonmnemonic behaviours that would directly influence their performance in the memory tasks.

The inherent problems in producing transgenic animals that consistently result in changes in behaviour that mask cognitive performance can be overcome using the administration of antisense oligonucleotides or RNA interference (RNAi) to prevent the translation of BDNF locally. The continuous intracerebroventricular infusion of antisense BDNF oligonucleotides in rats, with significant reduction of BDNF mRNA and protein levels in the hippocampus, resulted in impaired spatial learning in radial arm maze (Mizuno et al., 2000) and reduced LTP (Ma et al., 1998). Infusions of antisense cDNA acutely into the hippocampus that prevents the translation of endogenous BDNF prevented the consolidation of contextual fear conditioning, an effect that was reversed by co-administration of mBDNF (Lee et al., 2004). These latter investigations, which had the advantage of molecular technologies for manipulating BDNF levels in a regional and time-limited manner, clearly demonstrate BDNF has an essential and causal role in LTM processes. One similar study using RNAi with small interfering RNAs (siRNA) directed against BDNF mRNA, has shown that BDNF synthesis was necessary for phrenic long-term facilitation, a form of serotonin-dependent synaptic plasticity in the spinal cord (Baker-Herman et al., 2004). The success of this technique to test the role of BDNF in synaptic plasticity in vivo opens the way for extending the use of RNAi technology to the study of learning and memory in whole animal models.

BDNF has recently been shown to have an additional role in the maintenance of LTM after acquisition. Using two different hippocampal-dependent learning tasks, contextual fear conditioning and inhibitory avoidance, administration of BDNF-blocking antibodies during a restricted time window around $12 \mathrm{~h}$ after training blocked memory retention (Bekinschtein et al., 2007a). During this same time-window, mBDNF rescued the effect of protein synthesis inhibition on retention (Bekinschtein et al., 2008). This novel finding suggests that BDNF in the rat hippocampus is necessary and sufficient for the stabilization of recurrent rounds of consolidation-like protein synthesis-dependent processes essential for persistence of LTM.

The development of transgenic mice particularly those overexpressing BDNF, has also added new and contradictory information concerning the relationship between BDNF, LTP and learning and memory. Mice overexpressing the full-length TrkB receptor have improved cognitive skills but attenuated LTP (Koponen et al., 2004), and mice overexpressing a truncated form of the TrkB receptor show a memory deficit in the MWM but normal LTP (Saarelainen et al., 2000). These studies indicate that the requirement for TrkB-mediated signalling in LTM and LTP are different. Transgenic mice overexpressing BDNF under the $\beta$-actin promoter presented a $30-40 \%$ increase in the level of BDNF protein in the brain and revealed a LTP disruption in the CA1 area and a significant memory deficit in the passive avoidance test (Croll et al., 1999). This corresponded roughly to the same effect of attenuating BDNF activity. Similarly, more restricted overexpression of BDNF (two- to threefold depending on the structure) to the postnatal forebrain resulted in learning and memory impairments in both passive avoidance, eight-arm radial maze and MWM (Cunha et al., 2009). These studies suggest that BDNF may negatively regulate learning and memory and that too much as well as too little BDNF can impair LTM and LTP. These observations in transgenic mice overexpressing BDNF may reflect a developmental shift in the balance between inhibitory and excitatory transmission in the brain. Indeed, mutant mice overexpressing BDNF in the forebrain show an acceleration in the maturation of GABAergic innervation and inhibition in the visual cortex (Huang et al., 1999). This idea is supported by evidence that heterozygous BDNF KO mice show several deficits in interneuron maturation, including the altered expression of hallmark calcium binding proteins and peptide neurotransmitters (Jones et al., 1994). However, a general role for BDNF in modulating inhibitory circuitry is unknown. We here propose a model for the role of BDNF in modulating excitatory and inhibitory transmission in the brain and its functional consequences in learning and memory (Figure 5).

A functional association between synaptic activity and inhibitory signalling mediated by BDNF was reported over a decade ago. In cultured neurons from the visual cortex, the blockade of spontaneous activity reduced the number of GABAergic neurons, as well as the magnitude and frequency of spontaneous inhibitory postsynaptic currents and reduced the GABA-mediated inhibition of pyramidal cells, effects that were reversed by BDNF application (Rutherford et al., 1997). In addition, BDNF increased the frequency of miniature postsynaptic currents at both excitatory $\rightarrow$ excitatory neurons and excitatory $\rightarrow$ inhibitory neurons (Schinder et al., 2000). Thus, BDNF has an important function in controlling and regulating the balance between excitatory and inhibitory activity to maintain network function. In the adult neocortex, BDNF (via TrkB) controls the coordinated regulation of excitatory pyramidal cells and inhibitory interneurons, permitting scaling of synaptic responses to stabilize network activity (Rutherford et al., 1997; Desai et al., 1999). How exactly increases in glutamate and GABA release are integrated during learning and memory processes is still to be determined, but BDNF signalling may modulate an autoregulatory circuit between excitatory pyramidal cells and inhibitory interneurons, where specific signalling pathways are preferentially activated in time and in selective neuronal subtype. This kind of autoregulatory homeostasis (Turrigiano, 2007) may have an important contribution to metaplasticity, the so-called plasticity of plasticity by which neural activity at one point in time can change the ability of cells to undergo plasticity subsequently (Abraham, 2008). The link between metaplasticity and learning is not clear. However, there is evidence that learning induces alterations (histone acetylation and DNA methylation events) in the structure of the nuclear DNA-histone chromatin complex in gene promoter regions, important for regulating gene transcription, to directly affect new learning (Levenson 


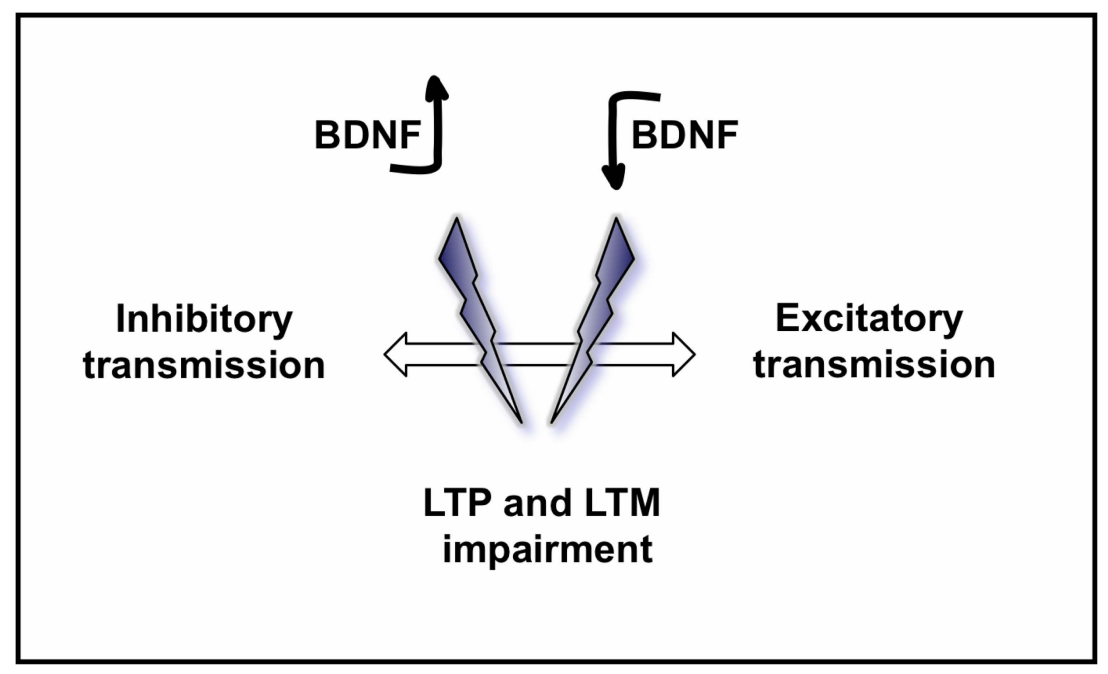

FIGURE 5 | Model proposed for the role of BDNF on excitatory and inhibitory circuits in the brain and its consequences on LTP and LTM. While a physiological amount of BDNF in the normal brain has been demonstrated to have positive effects on learning and memory, both an increased level of BDNF, and a decreased level of BDNF may disrupt the equilibrium between inhibitory and excitatory neurotransmission in the brain, leading to a loss of synaptic refinement and consequently impairing LTP, learning and memory. et al., 2004; Miller and Sweatt, 2007). This presents a molecular mechanism by which changes in behaviour are brought about by experience. The recent observation that chromatin remodelling following BDNF-dependent learning causes changes in the expression of exon-specific BDNF variants (Lubin et al., 2008), suggests not only that BDNF plays a role in the metaplasticity of memory but that selective variants may be preferentially involved.

\section{BDNF AND LTM RECONSOLIDATION AND EXTINCTION}

Although evidence has accumulated to show that BDNF has a critical role in the consolidation of LTM and LTP, few studies have addressed its contribution to other forms of LTM processes and plasticity, which include the reconsolidation and extinction of established LTM, and long-term depression (LTD).

Reconsolidation is the protein synthesis-dependent restabilization of the labile, active memory trace initiated by retrieval (reviewed in Nader, 2003; Alberini, 2005). It is viewed as a constructive mechanism for updating information content of an established memory. Initial studies indicated that unlike consolidation, the reconsolidation of contextual fear memory was not dependent on mBDNF in the hippocampus (Lee et al., 2004). As mentioned before, $\mathrm{mBDNF}$ is generated by the proteolytic cleavage of the precursor, proBDNF, by the tPA-mediated activation of plasmin (Seidah et al., 1996). Accordingly, the retrieval of contextual fear memory under conditions that favour reconsolidation were not correlated with alterations in the levels of proBDNF or mBDNF activity in CA1 (Barnes and Thomas, 2008), despite evidence that proBDNF is released in an activity dependent manner (Yang et al., 2009). Hence, BDNF has no apparent role in reconsolidation. In added proof, the updating (strengthening by additional learning events) of contextual fear memory relies on molecular processes supporting reconsolidation rather than consolidation (Lee, 2008).
Extinction occurs when a conditioned stimulus (CS) is presented without the reinforcement of a biologically salient unconditioned stimulus (US), and manifests as a weakening of the conditioned response. It is currently considered to be the generation of a new memory about a CS, a so-called CS-no US association (Bouton and Sunsay, 2003). Several studies have suggested a role for BDNF signalling in extinction. Mice with a hippocampus-specific deletion of BDNF induced in adulthood show impaired extinction of aversive memory (Heldt et al., 2007). Furthermore, the extinction of amygdala-dependent fear memory was dependent on TrkB activation in this region (Chhatwal et al., 2006). A recent study has indicated that decreased proteolysis of BDNF was correlated with the extinction of hippocampaldependent memory: extinction of contextual fear memory upregulated the levels of hippocampal proBDNF with respect to $\mathrm{mBDNF}$, and inhibition of tPA activity in the hippocampus potentiated extinction (Barnes and Thomas, 2008). The same study indicated that the proteolysis of BDNF regulated the consolidation of the CS-US association, however the proteolysis of proBDNF was a requirement for consolidation. These data indicate that formation of new memories relies on the regulation of proBDNF proteolysis, but the cleavage of proBDNF to $\mathrm{mBDNF}$ strengthens consolidation but attenuates extinction.

Similarly, opposing cellular actions of mBDNF and proBDNF have been described for synaptic plasticity (Lu et al., 2005). As mentioned above, the cleavage of proBDNF to mBDNF by tPA is essential for LTP in the hippocampus (Pang et al., 2004), whilst proBDNF-mediated signalling facilitates LTD in the hippocampus via the activation of the $\mathrm{p} 75^{\mathrm{NTR}}$ neurotrophin receptor (Woo et al., 2005). Evidence that hippocampal-dependent extinction is mediated by an increased proBDNF/mBDNF ratio may suggest that the synaptic and molecular events underlying extinction closely resemble LTD. The close correlation between the control 
of synaptic memory and the consolidation and extinction of LTM may additionally indicate that different forms of synaptic plasticity model distinct memory processes.

\section{STRUCTURAL SYNAPTIC CHANGES AND CELLULAR CHANGES MEDIATED BY BDNF IN PLASTICITY}

Permissive and instructive roles of BDNF in mediating synaptic plasticity in the CNS are well established (reviewed in Bramham and Messaoudi, 2005). The activity-driven and persistent increase in synaptic efficacy, the hallmark of LTP, is accompanied by ultrastructural changes in dendritic spines at excitatory glutamatergic synapses (Lee et al., 1980; Chang and Greenough, 1984; Geinisman et al., 1993; Harris et al., 2003). These changes include the formation of new spines (Engert and Bonhoeffer, 1999; Maletic-Savatic et al., 1999; Toni et al., 1999) and increases in the number of glutamatergic AMPA receptors in the dendritic spines (Isaac et al., 1995; Liao et al., 1995; Durand et al., 1996). The rapid increase in synapse area after LTP inducing stimulation results in changes in synapse shape and receptor availability, thus augmenting neurotransmission (Chen et al., 2007). Likewise, hippocampal-dependent learning is associated with similar synaptic rearrangements (Leuner et al., 2003; Knafo et al., 2004) as well as AMPA receptor trafficking into synapses in CA1 (Hu et al., 2007). BDNF can increase the number of dendritic spines in CA1 (Tyler and Pozzo-Miller, 2001; Alonso et al., 2004). Similarly BDNF overexpression increase dendritic complexity in hippocampal dentate gyrus (Tolwani et al., 2002). These data suggest that BDNF released in an activity-dependent manner (Aicardi et al., 2004) modulates the number and shape of dendritic spines in mature hippocampal neurons (Zagrebelsky et al., 2005). It will be interesting to see in future studies whether alterations in dendritic complexity mediated by BDNF are associated with learning and memory. LTP induced increases in spine density are themselves associated with rapid changes in stabilization of the actin cytoskeleton by the formation of polymerized actin, Factin (Lin et al., 2005). It has been recently reported that endogenous BDNF released during LTP induction in CA1 promotes F-actin formation in potentiated synapses by phosphorylation and attenuation of the activity of ADF/cofilin which normally acts to cleave polymerized actin (Rex et al., 2007). Although there are no studies directly investigating LTM yet, a recent study has shown that exposure to an enriched-environment, a form of experience-dependent learning, results in the phosphorylation of cofilin in the postsynaptic spines in CA1 and in a concomitant increase in their size (Fedulov et al., 2007). Native BDNF-induced increases in spine density are also dependent on the insertion of the nonselective cation channel, TRPC3 (Amaral and PozzoMiller, 2007). Interestingly, for classical conditioning in turtles, BDNF is required for AMPA receptor trafficking into activated synapses (Li and Keifer, 2008). TRPC3 channels may therefore emerge as novel effectors of BDNF-mediated dendritic remodelling, plasticity and LTM.

It is apparent that there is a correlation between the level of neurogenesis in the dentate gyrus and hippocampal-dependent memory (Zhao et al., 2008), and that new granule cells become selectively recruited into the existing hippocampal networks with learning (Kee et al., 2007). Furthermore it may be that co-ordinated apoptosis and neurogenesis mechanisms are especially important for memory formation, at least for some forms of hippocampaldependent learning (Dupret et al., 2007). However, it is not clear whether hippocampal neurogenesis is causal for LTM. There is no direct evidence for the involvement of BDNF in learning associated neurogenesis. Nevertheless, exposure to an enriched environment and exercise elevated the levels of BDNF in the hippocampus, increased neurogenesis and improved learning (Olson et al., 2006). The exact mechanisms by which apoptosis and neurogenesis facilitate memory formation and an exact role for BDNF in these two cellular processes remains to be fully understood.

The control of BDNF mRNA translation in dendrites may be particularly important for LTM. Memory is not only represented by an altered synaptic efficiency, it is also sparsely distributed across a neuronal and synapses network (Wilson and McNaughton, 1993; Guzowski et al., 1999; Repa et al., 2001; Perez-Orive et al., 2002; Rumpel et al., 2005). The regulated release of BDNF and the BDNFmediated translation at local synapses would modulate synaptic activity and neural connectivity specifically at active synapses, which ultimately form the distributed memory "engram". BDNF rapidly initiates the translation of several dendritically localized mRNAs associated with LTP and spine morphogenesis, including CaMKII, the GluR1 AMPA receptor and Arc/Arg3.1 (Yin et al., 2002; Schratt et al., 2004; Kanhema et al., 2006). In addition to the ERK and PLC $\gamma$ pathways, signalling through PI3K, Akt and downstream mTOR has been particularly implicated in regulating the activity of the translational machinery in response to BDNF-TrkB signalling (reviewed in Soule et al., 2006). mTOR contributes to persistent forms of LTP and LTD (Kelleher et al., 2004). It is also necessary for the consolidation (Bekinschtein et al., 2007b; Myskiw et al., 2008; Belelovsky et al., 2009) and reconsolidation (Blundell et al., 2008) of aversive memory. At least for inhibitory avoidance, activation of mTOR depends on hippocampal BDNF (Slipczuk et al., 2009).

\section{CONCLUSIONS}

BDNF has emerged as an important mediator of synaptic plasticity. It not only plays a role in LTP and LTD but it is perhaps the key instructor for plasticity-related processes underlying LTM. This is particularly exemplified by "rescue" studies where the addition of BDNF restores learning after endogenous depletion of BDNF. The key role for BDNF in LTM is further underscored because regulation of BDNF but not other members of the neurotrophin family is associated with LTM formation (Hall et al., 2000; Rattiner et al., 2004a; Hennigan et al., 2009). Nevertheless, other neurotrophins including NGF and NT3, in a similar manner to BDNF, may have a more specific role in the altered mnemonic processes associated with neurodegenerative diseases such as Alzheimer's and Parkinson's diseases, by promoting the survival of specific neuronal populations affected in these conditions (Williams et al., 1989; Chen and Tonegawa, 1997; Tong et al., 2004; Gu et al., 2009). To complicate the matter, consistent evidence now indicates that BDNF, especially when overexpressed, may preferentially stimulate inhibitory pathways and negatively affecting learning, thus considerably limiting its potential therapeutic use. Moreover, we still do not know what are the cellular processes necessary for the maintenance of LTM that are instructed by BDNF after learning. Nor whether 
separate BDNF-mediated processes are central to the persistence of memory after recall. A new generation of sophisticated genetic tools, including cell specific siRNA and overexpression studies, targeting individual BDNF variants and components of the downstream BDNF-TrkB and BDNF-p $75^{\mathrm{NTR}}$ signalling cascades, under precise spatial and temporal control within specific brain regions, are now necessary to unravel the complex roles of this fascinating and pleiotropic molecule in learning and memory processes.

\section{REFERENCES}

Aakalu, G., Smith, W. B., Nguyen, N., Jiang, C., and Schuman, E. M. (2001). Dynamic visualization of local protein synthesis in hippocampal neurons. Neuron 30, 489-502.

Abraham, W. C. (2008). Metaplasticity: tuning synapses and networks for plasticity. Nat. Rev. Neurosci. 9, 387.

Aicardi, G., Argilli, E., Cappello, S., Santi, S., Riccio, M., Thoenen, H., and Canossa, M. (2004). Induction of long-term potentiation and depression is reflected by corresponding changes in secretion of endogenous brain-derived neurotrophic factor. Proc. Natl. Acad. Sci. U.S.A. 101, 15788-15792.

Aid, T., Kazantseva, A., Piirsoo, M., Palm, K., and Timmusk, T. (2007). Mouse and rat BDNF gene structure and expression revisited. J. Neurosci. Res. 85, 525-535.

Akaneya, Y., Tsumoto, T., Kinoshita, S., and Hatanaka, H. (1997). Brainderived neurotrophic factor enhances long-term potentiation in rat visual cortex. J. Neurosci. 17, 6707-6716.

Alberini, C. M. (2005). Mechanisms of memory stabilization: are consolidation and reconsolidation similar or distinct processes? Trends Neurosci. 28, 51-56.

Alcantara, S., Frisen, J., del Rio, J. A., Soriano, E., Barbacid, M., and SilosSantiago, I. (1997). TrkB signaling is required for postnatal survival of CNS neurons and protects hippocampal and motor neurons from axotomyinduced cell death. J. Neurosci. 17, 3623-3633.

Alonso, M., Bekinschtein, P., Cammarota, M., Vianna, M. R., Izquierdo, I., and Medina, J. H. (2005). Endogenous $\mathrm{BDNF}$ is required for long-term memory formation in the rat parietal cortex. Learn. Mem. 12, 504-510.

Alonso, M., Medina, J. H., and PozzoMiller, L. (2004). ERK1/2 activation is necessary for BDNF to increase dendritic spine density in hippocampal CA1 pyramidal neurons. Learn. Mem. 11, 172-178.

Alonso, M., Vianna, M. R., Izquierdo, I., and Medina, J. H. (2002). Signaling mechanisms mediating BDNF modulation of memory formation in vivo in the hippocampus. Cell. Mol. Neurobiol. 22, 663-674.

Altar, C. A., and DiStefano, P. S. (1998). Neurotrophin trafficking by anterograde transport. Trends Neurosi. 21, 433-437.

Amaral, M. D., and Pozzo-Miller, L. (2007). TRPC3 channels are necessary for brain-derived neurotrophic factor to activate a nonselective cationic current and to induce dendritic spine formation. J. Neurosci. 27, 5179-5189.

Baker-Herman, T. L., Fuller, D. D., Bavis, R. W., Zabka, A. G., Golder, F. J., Doperalski, N. J., Johnson, R. A., Watters, J. J., and Mitchell, G. S. (2004). BDNF is necessary and sufficient for spinal respiratory plasticity following intermittent hypoxia. Nat. Neurosci. 7, 48-55.

Balkowiec, A., and Katz, D. M. (2002). Cellular mechanisms regulating activity-dependent release of native brain-derived neurotrophic factor from hippocampal neurons. J. Neurosci. 22, 10399-10407.

Barco, A., Patterson, S., Alarcon, J. M., Gromova, P., Mata-Roig, M., Morozov, A., and Kandel, E. R. (2005). Gene expression profiling of facilitated L-LTP in VP16-CREB mice reveals that BDNF is critical for the maintenance of LTP and its synaptic capture. Neuron 48, 123-137.

Barco, A., Pittenger, C., and Kandel, E. R. (2003). CREB, memory enhancement and the treatment of memory disorders: promises, pitfalls and prospects. Expert Opin. Ther. Targets 7, 101-114.

Barde, Y. A., Edgar, D., and Thoenen, H. (1982). Purification of a new neurotrophic factor from mammalian brain. EMBO J. 1, 549-553.

Barnes, P., and Thomas, K. L. (2008). Proteolysis of proBDNF is a key regulator in the formation of memory. PLoS ONE3, e3248. doi: 10.1371/journal.pone.0003248.

Bartoletti, A., Cancedda, L., Reid, S. W., Tessarollo, L., Porciatti, V., Pizzorusso, T., and Maffei, L. (2002). Heterozygous knock-out mice for brain-derived neurotrophic factor show a pathwayspecific impairment of long-term

\section{ACKNOWLEDGMENTS}

The authors acknowledge Fundação para a Ciência e a Tecnologia, Portugal, which, through the POCTI 2010 from the European Science Foundation, has financed research leading to the writing of this review (fellowship SFRH/BD/9625/2002 to Carla Cunha) and also the MJ Fox Foundation for Parkinson's Research, the Parkinson's Disease Society of the UK and the Italian Ministry of Health (to Riccardo Brambilla).

potentiation but normal critical period for monocular deprivation. $J$. Neurosci. 22, 10072-10077.

Bekinschtein, P., Cammarota, M., Igaz, L. M., Bevilaqua, L. R., Izquierdo, I., and Medina, J. H. (2007a). Persistence of long-term memory storage requires a late protein synthesis- and BDNFdependent phase in the hippocampus. Neuron 53, 261-277.

Bekinschtein, P., Katche, C., Slipczuk, L. N. Igaz, L. M., Cammarota, M., Izquierdo, I., and Medina, J. H. (2007b). mTOR signaling in the hippocampus is necessary for memory formation. Neurobiol. Learn. Mem. 87, 303-307.

Bekinschtein, P., Cammarota, M., Katche, C., Slipczuk, L., Rossato, J. I., Goldin, A., Izquierdo, I., and Medina, J. H. (2008). BDNF is essential to promote persistence of long-term memory storage. Proc. Natl. Acad. Sci. U.S.A. 105, 2711-2716

Belelovsky, K., Kaphzan, H., Elkobi, A., and Rosenblum, K. (2009). Biphasic activation of the mTOR pathway in the gustatory cortex is correlated with and necessary for taste learning. J. Neurosci. 29, 7424-7431.

Bliss, T. V., and Collingridge, G. L. (1993). A synaptic model of memory: longterm potentiation in the hippocampus. Nature 361, 31-39.

Blum, R., Kafitz, K. W., and Konnerth, A. (2002). Neurotrophin-evoked depolarization requires the sodium channel $\mathrm{Na}(\mathrm{V}) 1.9$. Nature 419, 687-693.

Blundell, J., Kouser, M., and Powell, C. M. (2008). Systemic inhibition of mammalian target of rapamycin inhibits fear memory reconsolidation. Neurobiol. Learn. Mem. 90, 28-35.

Bouton, M. E., and Sunsay, C. (2003). Importance of trials versus accumulating time across trials in partially reinforced appetitive conditioning. $J$. Exp. Psychol. 29, 62-77.

Bramham, C. R., and Messaoudi, E. (2005). BDNF function in adult synaptic plasticity: the synaptic consolidation hypothesis. Prog. Neurobiol. 76, 99-125.

Bramham, C. R., and Wells, D. G. (2007) Dendritic mRNA: transport, translation and function. Nat. Rev. Neurosci. 8, 776-789.
Bramham, C. R., Worley, P. F., Moore, M. J., and Guzowski, J. F. (2008). The immediate early gene arc/arg3.1: regulation, mechanisms, and function. $J$ Neurosci. 28, 11760-11767.

Canossa, M., Griesbeck, O., Berninger, B., Campana, G., Kolbeck, R., and Thoenen, H. (1997). Neurotrophin release by neurotrophins: implications for activity-dependent neuronal plasticity. Proc. Natl. Acad. Sci. U.S.A. 94, 13279-13286.

Castren, E., Pitkanen, M., Sirvio, J., Parsadanian, A., Lindholm, D. Thoenen, H., and Riekkinen, P. J. (1993). The induction of LTP increases BDNF and NGF mRNA but decreases NT-3 mRNA in the dentate gyrus. Neuroreport 4, 895-898.

Chang, F. L., and Greenough, W. T. (1984). Transient and enduring morphological correlates of synaptic activity and efficacy change in the rat hippocampal slice. Brain Res. 309, 35-46.

Chao, M. V. (2003). Neurotrophins and their receptors: a convergence point for many signalling pathways. Nat. Rev. Neurosci. 4, 299-309.

Chen, C., and Tonegawa, S. (1997). Molecular genetic analysis of synaptic plasticity, activity-dependent neural development, learning, and memory in the mammalian brain. Annu. Rev. Neurosci. 20, 157-184.

Chen, L., Tracy, T., and Nam, C. I. (2007). Dynamics of postsynaptic glutamate receptor targeting. Curr. Opin. Neurobiol. 17, 53-58.

Chen, Z. Y., Patel, P. D., Sant, G., Meng, C. X., Teng, K. K., Hempstead, B. L., and Lee, F. S. (2004). Variant brain-derived neurotrophic factor (BDNF) (Met66) alters the intracellular trafficking and activity-dependent secretion of wildtype BDNF in neurosecretory cells and cortical neurons. J. Neurosci. 24, 4401-4411.

Chhatwal, J. P., Stanek-Rattiner, L., Davis, M., and Ressler, K. J. (2006). Amygdala BDNF signaling is required for consolidation but not encoding of extinction. Nat. Neurosci. 9, 870-872.

Cirulli, F., Berry, A., Chiarotti, F., and Alleva, E. (2004). Intrahippocampal administration of BDNF in adult rats affects short-term behavioral 
plasticity in the Morris water maze and performance in the elevated plusmaze. Hippocampus 14, 802-807.

Cohen, S., Levi-Montalcini, R., and Hamburger, V. (1954). A nerve growth-stimulating factor isolated from sarcom as 37 and 180.Proc. Natl. Acad. Sci. U.S.A. 40, 1014-1018.

Croll, S. D., Suri, C., Compton, D. L., Simmons, M. V., Yancopoulos, G. D., Lindsay, R. M., Wiegand, S. J., Rudge, J. S., and Scharfman, H. E. (1999). Brainderived neurotrophic factor transgenic mice exhibit passive avoidance deficits, increased seizure severity and in vitro hyperexcitability in the hippocampus and entorhinal cortex. Neuroscience 93, 1491-1506.

Cunha, C., Angelucci, A., D'Antoni, A., Dobrossy, M. D., Dunnett, S. B., Berardi, N., and Brambilla, R. (2009). Brain-derived neurotrophic factor (BDNF) overexpression in the forebrain results in learning and memory impairments. Neurobiol. Dis. 33, 358-368.

Desai, N. S., Rutherford, L. C., and Turrigiano, G. G. (1999). BDNF regulates the intrinsic excitability of cortical neurons. Learn. Mem. 6, 284-291.

Dragunow, M., Beilharz, E., Mason, B., Lawlor, P., Abraham, W., and Gluckman, P. (1993). Brain-derived neurotrophic factor expression after long-term potentiation. Neurosci. Lett. $160,232-236$.

Dugich-Djordjevic, M. M., Peterson, C., Isono, F., Ohsawa, F., Widmer, H. R., Denton, T. L., Bennett, G. L., and Hefti, F. (1995). Immunohistochemical visualization of brain-derived neurotrophic factor in the rat brain. Eur. J. Neurosci. 7, 1831-1839.

Dupret, D., Fabre, A., Dobrossy, M. D., Panatier, A., Rodriguez, J.J., Lamarque, S., Lemaire, V., Oliet, S. H., Piazza, P. V., and Abrous, D. N. (2007). Spatial learning depends on both the addition and removal of new hippocampal neurons. PLoS Biol. 5, e214. doi: 10.1371/journal.pbio.0050214.

Durand, G. M., Kovalchuk, Y., and Konnerth, A. (1996). Long-term potentiation and functional synapse induction in developing hippocampus. Nature 381, 71-75.

Egan, M. F., Kojima, M., Callicott, J. H., Goldberg, T. E., Kolachana, B. S., Bertolino, A., Zaitsev, E., Gold, B., Goldman, D., Dean, M., Lu, B., and Weinberger, D. R. (2003). The BDNF val66met polymorphism affects activity-dependent secretion of BDNF and human memory and hippocampal function. Cell 112, 257-269.

Engert, F., and Bonhoeffer, T. (1999). Dendritic spine changes associated with hippocampal long-term synaptic plasticity. Nature 399, 66-70.
Ernfors, P., Lee, K. F., and Jaenisch, R. (1994). Mice lacking brain-derived neurotrophic factor develop with sensory deficits. Nature 368, 147-150.

Fedulov, V., Rex, C. S., Simmons, D. A., Palmer, L., Gall, C. M., and Lynch, G. (2007). Evidence that long-term potentiation occurs within individual hippocampal synapses during learning. J. Neurosci. 27, 8031-8039.

Figurov, A., Pozzo-Miller, L. D., Olafsson, P., Wang, T., and Lu, B. (1996). Regulation of synaptic responses to high-frequency stimulation and LTP by neurotrophins in the hippocampus. Nature 381, 706-709.

Finkbeiner, S., Tavazoie, S. F., Maloratsky, A., Jacobs, K. M., Harris, K. M., and Greenberg, M. E. (1997). CREB: a major mediator of neuronal neurotrophin responses. Neuron 19, 1031-1047.

Frank, L., Ventimiglia, R., Anderson, K., Lindsay, R. M., and Rudge, J. S. (1996). BDNF down-regulates neurotrophin responsiveness, $\operatorname{TrkB}$ protein and $\operatorname{TrkB}$ mRNA levels in cultured rat hippocampal neurons. Eur. J. Neurosci. 8, 1220-1230.

Freudenthal, R., Boccia, M. M., Acosta, G. B., Blake, M. G., Merlo, E., Baratti, C. M., and Romano, A. (2005). NFkappaB transcription factor is required for inhibitory avoidance long-term memory in mice. Eur. J. Neurosci. 21, 2845-2852.

Gartner, A., Polnau, D. G., Staiger, V., Sciarretta, C., Minichiello, L., Thoenen, H., Bonhoeffer, T., and Korte, M. (2006). Hippocampal long-term potentiation is supported by presynaptic and postsynaptic tyrosine receptor kinase B-mediated phospholipase Cgamma signaling. J. Neurosci. 26, 3496-3504.

Geinisman, Y., deToledo-Morrell, L., Morrell, F., Heller, R.E., Rossi, M., and Parshall, R. F. (1993). Structural synaptic correlate of long-term potentiation: formation of axospinous synapses with multiple, completely partitioned transmission zones. Hippocampus 3 , 435-445.

Ghosh, A., Carnahan, J., and Greenberg, M. E. (1994). Requirement for BDNF in activity-dependent survival of cortical neurons. Science 263, 1618-1623.

Gorski, J. A., Balogh, S. A., Wehner, J. M., and Jones, K. R. (2003). Learning deficits in forebrain-restricted brainderived neurotrophic factor mutant mice. Neuroscience 121, 341-354.

Griesbeck, O., Canossa, M., Campana, G., Gartner, A., Hoener, M. C., Nawa, H., Kolbeck, R., and Thoenen, H. (1999). Are there differences between the secretion characteristics of NGF and BDNF? Implications for the modulatory role of neurotrophins in activity-dependent neuronal plasticity Microsc. Res. Tech. 45, 262-275.

Gruart, A., Sciarretta, C., ValenzuelaHarrington, M., Delgado-Garcia, J.M., and Minichiello, L. (2007). Mutation at the TrkB PLC $\{$ gamma\}-docking site affects hippocampal LTP and associative learning in conscious mice. Learn. Mem. 14, 54-62.

Gu, S., Huang, H., Bi, J., Yao, Y., and Wen, T. (2009). Combined treatment of neurotrophin-3 gene and neural stem cells is ameliorative to behavior recovery of Parkinson's disease rat model. Brain Res. 1257, 1-9.

Guzowski, J. F., McNaughton, B. L., Barnes, C. A., and Worley, P. F. (1999). Environment-specific expression of the immediate-early gene Arc in hippocampal neuronal ensembles. Nat. Neurosci. 2, 1120-1124.

Haapasalo, A., Sipola, I., Larsson, K., Akerman, K. E., Stoilov, P., Stamm, S., Wong, G., and Castren, E. (2002). Regulation of TRKB surface expression by brain-derived neurotrophic factor and truncated TRKB isoforms. J. Biol. Chem. 277, 43160-43167.

Hall, J., Thomas, K. L., and Everitt, B. J. (2000). Rapid and selective induction of BDNF expression in the hippocampus during contextual learning. Nat. Neurosci. 3, 533-535.

Harris, K. M., Fiala, J. C., and Ostroff, L. (2003).Structural changes at dendritic spine synapses during long-term potentiation. Philos. Trans. R. Soc. Lond., B, Biol. Sci. 358, 745-748.

Hartmann, M., Heumann, R., and Lessmann, V. (2001). Synaptic secretion of BDNF after high-frequency stimulation of glutamatergic synapses. EMBO J. 20, 5887-5897.

Heldt, S. A., Stanek, L., Chhatwal, J.P., and Ressler, K. J. (2007). Hippocampusspecific deletion of BDNF in adult mice impairs spatial memory and extinction of aversive memories. Mol. Psychiatry 12, 656-670.

Hennigan, A., Callaghan, C. K., Kealy, J., Rouine, J., and Kelly, A. M. (2009). Deficits in LTP and recognition memory in the genetically hypertensive rat are associated with decreased expression of neurotrophic factors and their receptors in the dentate gyrus. Behav. Brain Res. 197, 371-377.

Henry, R. A., Hughes, S. M., and Connor, B. (2007). AAV-mediated delivery of BDNF augments neurogenesis in the normal and quinolinic acid-lesioned adult rat brain. Eur. J. Neurosci. 25, 3513-3525.

Hu, B., Nikolakopoulou, A. M., and Cohen-Cory, S. (2005). BDNF stabilizes synapses and maintains the structural complexity of optic axons in vivo. Development 132, 4285-4298.
Hu, H., Real, E., Takamiya, K., Kang, M. G., Ledoux, J., Huganir, R. L., and Malinow, R. (2007). Emotion enhances learning via norepinephrine regulation of AMPA-receptor trafficking. Cell 131, 160-173.

Huang, E. J., and Reichardt, L. F. (2003). Trk receptors: roles in neuronal signal transduction. Annu. Rev. Biochem. 72, 609-642.

Huang, Z. J., Kirkwood,A., Pizzorusso, T., Porciatti, V., Morales, B., Bear, M. F., Maffei, L., and Tonegawa, S. (1999). BDNF regulates the maturation of inhibition and the critical period of plasticity in mouse visual cortex. Cell 98, 739-755.

Ippolito, D. L., Temkin, P. A., Rogalski, S. L., and Chavkin, C. (2002). N-terminal tyrosine residues within the potassium channel Kir3 modulate GTPase activity of Galphai. J. Biol. Chem. 277, 32692-32696.

Isaac, J. T., Nicoll, R. A., and Malenka, R. C. (1995). Evidence for silent synapses: implications for the expression of LTP. Neuron 15, 427-434.

Itami, C., Kimura, F., Kohno, T., Matsuoka, M., Ichikawa, M., Tsumoto, T., and Nakamura, S. (2003). Brain-derived neurotrophic factor-dependent unmasking of "silent" synapses in the developing mouse barrel cortex. Proc. Natl. Acad. Sci. U.S.A. 100 , 13069-13074.

Jones, K. R., Farinas, I., Backus, C., and Reichardt, L. F. (1994). Targeted disruption of the BDNF gene perturbs brain and sensory neuron development but not motor neuron development. Cell 76, 989-999.

Jovanovic, J. N., Czernik, A. J., Fienberg A. A., Greengard, P., and Sihra, T. S. (2000). Synapsins as mediators of BDNF-enhanced neurotransmitter release. Nat. Neurosci. 3, 323-329.

Kafitz, K.W., Rose, C. R., Thoenen, H., and Konnerth, A. (1999). Neurotrophinevoked rapid excitation through TrkB receptors. Nature 401, 918-921.

Kang, H., and Schuman, E. M. (1995). Long-lasting neurotrophin-induced enhancement of synaptic transmission in the adult hippocampus. Science 267, 1658-1662.

Kang, H., Welcher, A. A., Shelton, D., and Schuman,E.M. (1997). Neurotrophins and time: different roles for TrkB signaling in hippocampal long-term potentiation. Neuron 19, 653-664.

Kanhema, T., Dagestad, G., Panja, D., Tiron, A., Messaoudi, E., Havik, B., Ying, S. W., Nairn, A. C., Sonenberg, N., and Bramham, C. R. (2006). Dual regulation of translation initiation and peptide chain elongation during BDNF-induced LTP in vivo: evidence for compartment-specific translation control. J. Neurochem. 99, 1328-1337. 
Kaplan, D. R., and Miller, F. D. (2000). Neurotrophin signal transduction in the nervous system. Curr. Opin. Neurobiol. 10, 381-391.

Kawamoto, Y., Nakamura, S., Nakano, S., Oka, N., Akiguchi, I., and Kimura, J. (1996). Immunohistochemical localization of brain-derived neurotrophic factor in adult rat brain. Neuroscience 74, 1209-1226.

Kee, N., Teixeira, C. M., Wang, A. H., and Frankland, P. W. (2007). Preferential incorporation of adult-generated granule cells into spatial memory networks in the dentate gyrus. Nat. Neurosci. 10, 355-362.

Kelleher, R. J. III, Govindarajan, A., and Tonegawa, S. (2004). Translational regulatory mechanisms in persistent forms of synaptic plasticity. Neuron 44, 59-73.

Kesslak, J. P., So, V., Choi, J., Cotman, C. W., and Gomez-Pinilla, F. (1998). Learning upregulates brain-derived neurotrophic factor messenger ribonucleic acid: a mechanism to facilitate encoding and circuit maintenance? Behav. Neurosci. 112, 1012-1019.

Klann, E., and Dever, T. E. (2004). Biochemical mechanisms for translational regulation in synaptic plasticity. Nat. Rev. Neurosci. 5, 931-942.

Klein, R., Conway, D., Parada, L. F., and Barbacid, M. (1990). The trkB tyrosine protein kinase gene codes for a second neurogenic receptor that lacks the catalytic kinase domain. Cell 61, 647-656.

Klein, R., Smeyne, R. J., Wurst, W., Long, L. K., Auerbach, B. A., Joyner, A. L., and Barbacid, M. (1993). Targeted disruption of the trkB neurotrophin receptor gene results in nervous system lesions and neonatal death. Cell 75, 113-122.

Knafo, S., Ariav, G., Barkai, E., and Libersat, F. (2004). Olfactory learninginduced increase in spine density along the apical dendrites of CAl hippocampal neurons. Hippocampus 14, 819-825.

Koponen, E., Voikar, V., Riekki, R., Saarelainen, T., Rauramaa, T., Rauvala, H., Taira, T., and Castren, E. (2004). Transgenic mice overexpressing the full-length neurotrophin receptor trkB exhibit increased activation of the trkB-PLCgamma pathway, reduced anxiety, and facilitated learning. Mol. Cell. Neurosci. 26, 166-181.

Korte, M., Carroll, P., Wolf, E., Brem, G., Thoenen, H., and Bonhoeffer, T. (1995). Hippocampal long-term potentiation is impaired in mice lacking brain-derived neurotrophic factor. Proc. Natl. Acad. Sci. U.S.A. 92, 8856-8860.

Korte, M., Kang, H., Bonhoeffer, T., and Schuman, E. (1998). A role for BDNF in the late-phase of hippocampal longterm potentiation. Neuropharmacology 37, 553-559.

Lee, J. L. (2008). Memory reconsolidation mediates the strengthening of memories by additional learning. Nat Neurosci. 11, 1264-1266.

Lee, J. L., Everitt, B. J., and Thomas, K. L. (2004). Independent cellular processes for hippocampal memory consolidation and reconsolidation. Science 304, 839-843.

Lee, K. S., Schottler, F., Oliver, M., and Lynch, G. (1980). Brief bursts of high-frequency stimulation produce two types of structural change in rat hippocampus. J. Neurophysiol. 44, 247-258.

Lessmann, V., Gottmann, K., and Malcangio, M. (2003). Neurotrophin secretion: current facts and future prospects. Prog. Neurobiol. 69, 341-374.

Leuner, B., Falduto, J., and Shors, T. J. (2003). Associative memory formation increases the observation of dendritic spines in the hippocampus. J. Neurosci. 23, 659-665.

Levenson, J. M., O’Riordan, K. J., Brown, K. D., Trinh, M. A., Molfese, D. L., and Sweatt, J. D. (2004). Regulation of histone acetylation during memory formation in the hippocampus. J. Biol. Chem. 279, 40545-40559.

Li, H. S., Xu, X. Z., and Montell, C. (1999). Activation of a TRPC3-dependent cation current through the neurotrophin BDNF. Neuron 24, 261-273.

Li, W., and Keifer, J. (2008). Coordinate action of pre- and postsynaptic brainderived neurotrophic factor is required for AMPAR trafficking and acquisition of in vitro classical conditioning. Neuroscience 155, 686-697.

Li,W., and Keifer,J. (2009). BDNF-induced synaptic delivery of AMPAR subunits is differentially dependent on NMDA receptors and requires ERK. Neurobiol. Learn. Mem. 91, 243-249.

Liao, D., Hessler, N. A., and Malinow, R. (1995). Activation of postsynaptically silent synapses during pairing-induced LTP in CA1 region of hippocampal slice. Nature 375, 400-404.

Lin, B., Kramar, E. A., Bi, X., Brucher, F. A., Gall, C. M., and Lynch, G. (2005). Theta stimulation polymerizes actin in dendritic spines of hippocampus. J. Neurosci. 25, 2062-2069.

Lin, C. H., Yeh, S. H., Lu, K. T., Leu, T. H., Chang, W. C., and Gean, P. W. (2001). A role for the PI-3 kinase signaling pathway in fear conditioning and synaptic plasticity in the amygdala. Neuron 31, 841-851.

Linnarsson, S., Bjorklund, A., and Ernfors, P. (1997). Learning deficit in BDNF mutant mice. Eur. J. Neurosci. 9, 2581-2587.
Liu, Q. R., Lu, L., Zhu, X. G., Gong, J. P. Shaham, Y., and Uhl, G. R. (2006) Rodent BDNF genes, novel promoters, novel splice variants, and regulation by cocaine. Brain Res. 1067, 1-12.

Liu,Q.R.,Walther,D., Drgon, T., Polesskaya, O., Lesnick, T. G., Strain, K. J., de Andrade, M., Bower, J.H., Maraganore, D. M., and Uhl, G. R. (2005). Human brain derived neurotrophic factor (BDNF) genes, splicing patterns, and assessments of associations with substance abuse and Parkinson's disease. Am. J. Med. Genet. B Neuropsychiatr. Genet. 134, 93-103.

Lu, B., and Figurov, A. (1997). Role of neurotrophins in synapse development and plasticity. Rev. Neurosci. 8 , $1-12$.

Lu, B., Pang, P. T., and Woo, N. H (2005). The yin and yang of neurotrophin action. Nat. Rev. Neurosci. 6, 603-614.

Lu, L., Dempsey, J., Liu, S. Y., Bossert, J. M. and Shaham, Y. (2004). A single infusion of brain-derived neurotrophic factor into the ventral tegmental area induces long-lasting potentiation of cocaine seeking after withdrawal. J. Neurosci. 24, 1604-1611.

Lubin, F. D., Roth, T. L., and Sweatt, J. D. (2008). Epigenetic regulation of BDNF gene transcription in the consolidation of fear memory. J. Neurosci. 28 10576-10586.

Lyons, W. E., Mamounas, L. A., Ricaurte, G. A., Coppola, V., Reid, S. W., Bora, S. H., Wihler, C., Koliatsos, V. E., and Tessarollo, L. (1999). Brain-derived neurotrophic factor-deficient mice develop aggressiveness and hyperphagia in conjunction with brain serotonergic abnormalities. Proc. Natl. Acad. Sci. U.S.A. 96, 15239-15244.

Ma, Y. L., Wang, H. L., Wu, H. C., Wei, C. L., and Lee, E. H. (1998). Brainderived neurotrophic factor antisense oligonucleotide impairs memory retention and inhibits long-term potentiation in rats. Neuroscience 82 957-967.

Maletic-Savatic, M., Malinow, R., and Svoboda, K. (1999). Rapid dendritic morphogenesis in CAl hippocampal dendrites induced by synaptic activity. Science 283, 1923-1927.

Mamounas, L.A., Blue, M. E., Siuciak, J.A., and Altar, C. A. (1995). Brain-derived neurotrophic factor promotes the survival and sprouting of serotonergic axons in rat brain. J. Neurosci. 15, 7929-7939.

Martin, S. J., Grimwood, P. D., and Morris, R. G. (2000). Synaptic plasticity and memory: an evaluation of the hypothesis. Annu. Rev. Neurosci. 23, 649-711.

McAllister, A. K., Katz, L. C., and Lo, D. C. (1997). Opposing roles for endogenous BDNF and NT-3 in regulating cortical dendritic growth. Neuron 18, 767-778.

McAllister, A. K., Lo, D. C., and Katz, L. C. (1995). Neurotrophins regulate dendritic growth in developing visual cortex. Neuron 15, 791-803.

Merlo, E., Freudenthal, R., Maldonado, H. and Romano, A. (2005). Activation of the transcription factor NF-kappaB by retrieval is required for long-term memory reconsolidation. Learn. Mem. 12, 23-29.

Messaoudi, E., Ying, S. W., Kanhema, T., Croll,S.D., and Bramham,C.R. (2002). Brain-derived neurotrophic factor triggers transcription-dependent, late phase long-term potentiation in vivo. J. Neurosci. 22, 7453-7461.

Miller, C. A., and Sweatt, J. D. (2007). Covalent modification of DNA regulates memory formation. Neuron 53, 857-869.

Minichiello, L., Calella, A. M., Medina, D. L., Bonhoeffer, T., Klein, R., and Korte, M. (2002). Mechanism of TrkBmediated hippocampal long-term potentiation. Neuron 36, 121-137.

Minichiello, L., and Klein, R. (1996). TrkB and TrkC neurotrophin receptors cooperate in promoting survival of hippocampal and cerebellar granule neurons. Genes Dev. 10, 2849-2858.

Minichiello, L., Korte, M., Wolfer, D., Kuhn, R., Unsicker, K., Cestari, V., Rossi-Arnaud, C., Lipp, H. P., Bonhoeffer, T., and Klein, R. (1999). Essential role for TrkB receptors in hippocampus-mediated learning. Neuron 24, 401-414.

Mizuno, M., Yamada, K., Olariu, A., Nawa, H., and Nabeshima, T. (2000). Involvement of brain-derived neurotrophic factor in spatial memory formation and maintenance in a radial arm maze test in rats. J. Neurosci. 20, 7116-7121.

Monteggia, L. M., Barrot, M., Powell, C. M., Berton, O., Galanis, V., Gemelli, T., Meuth, S., Nagy, A., Greene, R. W., and Nestler, E. J. (2004). Essential role of brain-derived neurotrophic factor in adult hippocampal function. Proc. Natl. Acad. Sci. U.S.A. 101, 10827-10832.

Mowla, S. J., Farhadi, H. F., Pareek, S., Atwal, J. K., Morris, S. J., Seidah, N. G., and Murphy, R.A. (2001). Biosynthesis and post-translational processing of the precursor to brain-derived neurotrophic factor. J. Biol. Chem. 276, 12660-12666.

Mu, J. S., Li, W. P., Yao, Z. B., and Zhou, X. F. (1999). Deprivation of endogenous brain-derived neurotrophic factor results in impairment of spatial learning and memory in adult rats. Brain Res. 835, 259-265. 
Murer, M. G., Yan, Q., and RaismanVozari, R. (2001). Brain-derived neurotrophic factor in the control human brain, and in Alzheimer's disease and Parkinson's disease. Prog. Neurobiol. 63, 71-124.

Myskiw, J. C., Rossato, J. I., Bevilaqua, L. R., Medina, J. H., Izquierdo, I., and Cammarota, M. (2008). On the participation of mTOR in recognition memory. Neurobiol Learn Mem 89, 338-351.

Nader, K. (2003). Neuroscience: rerecording human memories. Nature 425, 571-572.

Narisawa-Saito, M., Iwakura, Y., Kawamura, M., Araki, K., Kozaki, S., Takei, N., and Nawa, H. (2002). Brainderived neurotrophic factor regulates surface expression of alpha-amino3-hydroxy-5-methyl-4-isoxazoleproprionic acid receptors by enhancing the N-ethylmaleimide-sensitive factor/GluR2 interaction in developing neocortical neurons. J. Biol. Chem. 277, 40901-40910.

Olson, A. K., Eadie, B. D., Ernst, C., and Christie, B. R. (2006). Environmental enrichment and voluntary exercise massively increase neurogenesis in the adult hippocampus via dissociable pathways. Hippocampus 16, 250-260.

Orban, P. C., Chapman, P. F., and Brambilla, R. (1999). Is the RasMAPK signalling pathway necessary for long-term memory formation? Trends Neurosci. 22, 38-44.

Ou, L. C., and Gean, P. W. (2007). Transcriptional regulation of brainderived neurotrophic factor in the amygdala during consolidation of fear memory. Mol. Pharmacol. 72, 350-358.

Pang, P. T., Teng, H. K., Zaitsev, E., Woo, N. T., Sakata, K., Zhen, S., Teng, K. K., Yung, W. H., Hempstead, B. L., and Lu, B. (2004). Cleavage of proBDNF by tPA/plasmin is essential for longterm hippocampal plasticity. Science 306, 487-491.

Patterson, S. L., Abel, T., Deuel, T. A., Martin, K. C., Rose, J. C., and Kandel, E. R. (1996). Recombinant BDNF rescues deficits in basal synaptic transmission and hippocampal LTP in BDNF knockout mice. Neuron 16, 1137-1145.

Patterson, S. L., Pittenger, C., Morozov, A., Martin, K. C., Scanlin, H., Drake, C., and Kandel, E. R. (2001). Some forms of cAMP-mediated long-lasting potentiation are associated with release of BDNF and nuclear translocation of phospho-MAP kinase. Neuron 32, 123-140.

Perez-Orive, J., Mazor, O., Turner, G. C., Cassenaer, S., Wilson, R. I., and Laurent, G. (2002). Oscillations and sparsening of odor representations in the mushroom body. Science 297 359-365.

Poo, M. M. (2001). Neurotrophins as synaptic modulators. Nat. Rev. Neurosci. 2, 24-32.

Pozzo-Miller, L. D., Gottschalk, W., Zhang, L., McDermott, K., Du, J., Gopalakrishnan, R., Oho, C., Sheng, Z. H., and Lu, B. (1999). Impairments in high-frequency transmission, synaptic vesicle docking, and synaptic protein distribution in the hippocampus of BDNF knockout mice. J. Neurosci. 19, 4972-4983.

Rattiner, L. M., Davis, M., French, C. T., and Ressler, K. J. (2004a). Brainderived neurotrophic factor and tyrosine kinase receptor B involvement in amygdala-dependent fear conditioning. J. Neurosci. 24, 4796-4806.

Rattiner, L. M., Davis, M., and Ressler, K. J. (2004b). Differential regulation of brain-derived neurotrophic factor transcripts during the consolidation of fear learning. Learn. Mem. 11, 727-731.

Repa, J. C., Muller, J., Apergis, J., Desrochers, T. M., Zhou, Y., and LeDoux, J. E. (2001). Two different lateral amygdala cell populations contribute to the initiation and storage of memory. Nat. Neurosci. 4, 724-731.

Rex, C. S., Lin, C. Y., Kramar, E. A., Chen, L. Y., Gall, C. M., and Lynch, G. (2007). Brain-derived neurotrophic factor promotes long-term potentiationrelated cytoskeletal changes in adult hippocampus. J. Neurosci. 27, 3017-3029.

Rose, C. R., Blum, R., Kafitz, K. W., Kovalchuk, Y., and Konnerth, A. (2004). From modulator to mediator: rapid effects of BDNF on ion channels. Bioessays 26, 1185-1194.

Rumpel, S., LeDoux, J., Zador, A., and Malinow, R. (2005). Postsynaptic receptor trafficking underlying a form of associative learning. Science 308, 83-88.

Rutherford,L.C., DeWan,A., Lauer,H.M., and Turrigiano, G. G. (1997). Brainderived neurotrophic factor mediates the activity-dependent regulation of inhibition in neocortical cultures. $J$. Neurosci. 17, 4527-4535.

Saarelainen, T., Pussinen, R., Koponen, E. Alhonen, L., Wong, G., Sirvio, J., and Castren, E. (2000). Transgenic mice overexpressing truncated trkB neurotrophin receptors in neurons have impaired long-term spatial memory but normal hippocampal LTP. Synapse 38, 102-104.

Sairanen, M., Lucas, G., Ernfors, P., Castren, M., and Castren, E. (2005). Brain-derived neurotrophic factor and antidepressant drugs have different but coordinated effects on neuronal turnover, proliferation, and survival in the adult dentate gyrus. J. Neurosci. 25, 1089-1094.

Scharfman, H., Goodman, J., Macleod, A., Phani, S., Antonelli, C., and Croll, S. (2005). Increased neurogenesis and the ectopic granule cells after intrahippocampal BDNF infusion in adult rats. Exp. Neurol. 192, 348-356.

Schinder, A. F., Berninger, B., and Poo, M. (2000). Postsynaptic target specificity of neurotrophin-induced presynaptic potentiation. Neuron 25, 151-163.

Schratt, G.M., Nigh, E.A., Chen, W.G., Hu, L., and Greenberg, M.E. (2004). BDNF regulates the translation of a select group of mRNAs by a mammalian target of rapamycin-phosphatidylinositol 3-kinase-dependent pathway during neuronal development. J. Neurosci. 24, 7366-7377.

Segal, R. A. (2003). Selectivity in neurotrophin signaling: theme and variations. Annu. Rev. Neurosci. 26, 299-330.

Seidah, N. G., Benjannet, S., Pareek, S., Chretien, M., and Murphy, R. A. (1996). Cellular processing of the neurotrophin precursors of NT3 and BDNF by the mammalian proprotein convertases. FEBS Lett. 379, 247-250.

Slipczuk, L., Bekinschtein, P., Katche, C. Cammarota, M., Izquierdo, I., and Medina, J. H. (2009). BDNF activates mTOR to regulate GluR1 expression required for memory formation. PLoS ONE 4, e6007. doi: 10.1371/journal. pone.0006007.

Soule, J., Messaoudi, E., and Bramham, C. R. (2006). Brain-derived neurotrophic factor and control of synaptic consolidation in the adult brain. Biochem. Soc. Trans. 34, 600-604.

Sweatt, J. D. (2004). Mitogen-activated protein kinases in synaptic plasticity and memory. Curr. Opin. Neurobiol. 14, 311-317.

Taniguchi, N., Takada, N., Kimura, F., and Tsumoto, T. (2000). Actions of brain-derived neurotrophic factor on evoked and spontaneous EPSCs dissociate with maturation of neurones cultured from rat visual cortex. $J$. Physiol. 527(Pt. 3), 579-592.

Teng, H. K., Teng, K. K., Lee, R., Wright, S., Tevar, S., Almeida, R. D., Kermani, P., Torkin, R., Chen, Z. Y., Lee, F. S., Kraemer, R. T., Nykjaer, A., and Hempstead, B. L. (2005). ProBDNF induces neuronal apoptosis via activation of a receptor complex of p75NTR and sortilin. J. Neurosci. 25, 5455-5463.

Thomas, G. M., and Huganir, R. L. (2004). MAPK cascade signalling and synaptic plasticity. Nat. Rev. Neurosci. 5, 173-183.

Tolwani, R. J., Buckmaster, P. S., Varma, S., Cosgaya, J. M., Wu, Y., Suri, C., and Shooter, E. M. (2002). BDNF overexpression increases dendrite complexity in hippocampal dentate gyrus. Neuroscience 114, 795-805.

Tong, J., Fitzmaurice, P. S., Ang, L. C. Furukawa, Y., Guttman, M., and Kish, S. J. (2004). Brain dopaminestimulated adenylyl cyclase activity in Parkinson's disease, multiple system atrophy, and progressive supranuclear palsy. Ann. Neurol. 55, 125-129.

Tongiorgi, E. (2008). Activity-dependent expression of brain-derived neurotrophic factor in dendrites: facts and open questions. Neurosci. Res. 61, 335-346.

Tongiorgi, E., Righi, M., and Cattaneo, A. (1997). Activity-dependent dendritic targeting of BDNF and TrkB mRNAs in hippocampal neurons. J. Neurosci. 17, 9492-9505.

Toni, N., Buchs, P. A., Nikonenko, I., Bron, C. R., and Muller, D. (1999). LTP promotes formation of multiple spine synapses between a single axon terminal and a dendrite. Nature 402, 421-425.

Tucker, K., and Fadool, D. A. (2002). Neurotrophin modulation of voltage-gated potassium channels in rat through $\operatorname{TrkB}$ receptors is time and sensory experience dependent. $J$. Physiol. 542, 413-429.

Turrigiano, G. (2007). Homeostatic signaling: the positive side of negative feedback. Curr. Opin. Neurobiol. 17, 318-324.

Tyler,W. J., and Pozzo-Miller, L. D. (2001). BDNF enhances quantal neurotransmitter release and increases the number of docked vesicles at the active zones of hippocampal excitatory synapses. J. Neurosci. 21, 4249-4258.

West, A. E., Griffith, E. C., and Greenberg, M. E. (2002). Regulation of transcription factors by neuronal activity. Nat. Rev. Neurosci. 3, 921-931.

Williams, L. R., Jodelis, K. S., and Donald, M. R. (1989). Regional stimulation of cholinergic function by nerve growth factor in an animal model of Alzheimer's disease. Prog. Clin. Biol. Res. 317, 1179-1192.

Wilson, M. A., and McNaughton, B. L. (1993). Dynamics of the hippocampal ensemble code for space. Science 261, 1055-1058.

Woo, N. H., Teng, H. K., Siao, C. J., Chiaruttini, C., Pang, P. T., Milner, T. A., Hempstead, B. L., and Lu, B. (2005). Activation of p75NTR by proBDNF facilitates hippocampal long-term depression. Nat. Neurosci. 8, 1069-1077.

Wu, L., Wells, D., Tay, J., Mendis, D., Abbott, M. A., Barnitt, A., Quinlan, E., Heynen, A., Fallon, J. R., and Richter, J. D. (1998). CPEB-mediated cytoplasmic polyadenylation and the regulation of experience-dependent 
translation of alpha-CaMKII mRNA at synapses. Neuron 21, 1129-1139.

Yamada, M., Ohnishi, H., Sano, S., Nakatani,A., Ikeuchi, T., and Hatanaka, H. (1997). Insulin receptor substrate (IRS)- 1 and IRS-2 are tyrosine-phosphorylated and associated with phosphatidylinositol 3-kinase in response to brain-derived neurotrophic factor in cultured cerebral cortical neurons. J. Biol. Chem. 272, 30334-30339.

Yang, J., Siao, C. J., Nagappan, G., Marinic, T., Jing, D., McGrath, K., Chen, Z. Y., Mark, W., Tessarollo, L., Lee, F. S., Lu, B., and Hempstead, B. L. (2009). Neuronal release of proBDNF. Nat. Neurosci. 12, 113-115.

Yeh, S. H., Lin, C. H., Lee, C. F., and Gean, P. W. (2002). A requirement of nuclear factor-kappaB activation in fear-potentiated startle. J. Biol. Chem. 277, 46720-46729.
Yin, Y., Edelman, G. M., and Vanderklish, P. W. (2002). The brain-derived neurotrophic factor enhances synthesis of Arc in synaptoneurosomes. Proc. Natl. Acad. Sci. U.S.A. 99, 2368-2373.

Ying, S. W., Futter, M., Rosenblum, K., Webber, M. J., Hunt, S. P., Bliss, T. V., and Bramham, C. R. (2002). Brainderived neurotrophic factor induces long-term potentiation in intact adult hippocampus: requirement for ERK activation coupled to CREB and upregulation of Arc synthesis. J. Neurosci. 22, 1532-1540.

Young, K. M., Merson, T. D., Sotthibundhu, A., Coulson, E. J., and Bartlett, P. F. (2007). p75 neurotrophin receptor expression defines a population of BDNF-responsive neurogenic precursor cells. J. Neurosci. 27, 5146-5155.
Zagrebelsky, M., Holz, A., Dechant, G., Barde, Y.A., Bonhoeffer, T., and Korte, M. (2005). The p75 neurotrophin receptor negatively modulates dendrite complexity and spine density in hippocampal neurons. J. Neurosci. 25, 9989-9999.

Zhao, N., Zhong, C., Wang, Y., Zhao, Y., Gong, N., Zhou, G., Xu, T., and Hong, Z. (2008). Impaired hippocampal neurogenesis is involved in cognitive dysfunction induced by thiamine deficiency at early prepathological lesion stage. Neurobiol. Dis. 29, 176-185.

Zheng, W. H., and Quirion, R. (2004). Comparative signaling pathways of insulin-like growth factor- 1 and brain-derived neurotrophic factor in hippocampal neurons and the role of the PI3 kinase pathway in cell survival. J. Neurochem. 89, 844-852.
Conflict of Interest Statement: The authors declare that the research was conducted in the absence of any commercial or financial relationships that could be construed as a potential conflict of interest.

Received: 19 July 2009; paper pending published: 08 October 2009; accepted: 15 January 2010; published online: 09 February 2010.

Citation: Cunha C, BrambillaRand Thomas KL (2010) A simple role for BDNF in learning and memory? Front. Mol. Neurosci. 3:1. doi: 10.3389/neuro.02.001.2010 Copyright (c) 2010 Cunha, Brambilla and Thomas. This is an open-access article subject to an exclusive license agreement between the authors and the Frontiers Research Foundation, which permits unrestricted use, distribution, and reproduction in any medium, provided the original authors and source are credited. 